\title{
Education's Role in China's Structural Transformation*
}

\author{
Soohyung Lee \\ Benjamin A. Malin \\ University of Maryland and MPRC \\ Federal Reserve Board \\ LeeS@econ.umd.edu \\ benjamin.a.malin@frb.gov
}

September 2, 2009

\begin{abstract}
We explore education's role in improving the allocation of labor between China's agricultural and nonagricultural sectors and measure the portion of China's recent growth attributable to this channel. Building from micro-level estimates, we find that education's impact on labor reallocation between sectors accounts for about 9 percent of Chinese growth, whereas its impact on within-sector human capital growth explains only 2 percent. Our findings suggest that, when frictions cause large productivity gaps across sectors and returns to education are greater in the higher-productivity sectors, education policy may be a useful tool for increasing efficiency.
\end{abstract}

Keywords: Returns to Education; Structural Transformation; China; Labor Reallocation; Growth

JEL Classification Numbers: O1; O5; I2; J6; N3.

*An earlier version of this paper circulated under the title "The Role of Education in Economic Growth through the Sectoral Reallocation of Labor". We have benefitted from discussions with participants of the Stanford macro bag lunch, Stanford labor-development seminar, 2006 SED, 2007 PACDEV, and Federal Reserve Board lunch seminar. We thank Dongfang Shao for providing access to a digital version of the CSY data sets and Shufa Du for answering numerous questions regarding the CHNS. Lee acknowledges the Taube Fellowship for financial support. The views expressed here are those of the authors and do not necessarily reflect the views of the Federal Reserve System. 


\section{Introduction}

A burgeoning literature in development economics suggests that barriers to the efficient allocation of inputs are important for explaining why some countries have much lower income per capita than others. Because such barriers - whether to technological adoption (Parente and Prescott 1994), labor force mobility (Hayashi and Prescott 2008), or the flow of physical and human capital to their most productive uses (Vollrath 2009) - depress income levels, it follows that reductions in these barriers can lead to periods of rapid economic growth. Such growth may also be accompanied by a structural transformation of the economy as the employment and output shares of low-productivity sectors decrease, and factors of production move into high-productivity sectors.

The recent growth experience of China appears to be consistent with the effects of reduced barriers. Since 1978, when the Open Door policy reforms began, output per worker has increased at a very rapid pace $\mathrm{I}^{1}$ Moreover, this growth has been accompanied by a declining employment share for the agricultural sector from 71 percent in 1978 to 47 percent in 2004 (China Statistical Yearbooks), a phenomenon called labor reallocation. Given that large productivity differences exist between the agricultural and nonagricultural sectors, estimates of the fraction of growth in aggregate output per worker accounted for by labor reallocation are quite sizable, ranging between 25 and 33 percent (Brandt, Hsieh and Zhu (2008) and Dekle and Vandenbroucke (2006), respectively).

Although many factors undoubtedly contributed to labor reallocation, in this paper we use detailed micro-level data to quantify the role of one particular driving force: increased educational attainment. Our focus on education stems from the ability of educated workers to overcome the labor market restrictions present in China (e.g., migration regulations based on the hukou system). Our hypothesis is that increased education effectively reduced the inefficiencies caused by these restrictions, thus spurring growth. We undertake a growth accounting exercise to measure education's impact on growth through enabling labor reallocation between sectors. To provide a metric for assessing the importance of this channel, we also measure education's contribution through raising human capital within sectors.2

\footnotetext{
${ }^{1}$ For example, Young (2003) estimates growth in aggregate output per worker of 5.2 percent from 1978 to 1998; Brandt, Hsieh, and Zhu (2008) report growth of 6.96 percent from 1978 to 2004; and Dekle and Vandenbroucke (2006) report growth of 5.7 percent from 1978 to 2003.

${ }^{2}$ Education's impact on human capital has long been considered an important way in which education affects income. See, for example, labor studies following Mincer (1974) and cross-country studies such as Bils and Klenow (2000).
} 
We utilize a model with finite-lived individuals in which income is a function of an individual's observable (e.g, gender) and unobservable (e.g, sector-specific ability) characteristics. Following Mincer (1974), we assume education increases the human capital of workers, possibly at a different rate in each sector. In addition, education affects the cost of working in the nonagricultural sector relative to the agricultural sector. Individuals choose their education level and sector of employment to maximize the expected net present discounted value of their lifetime income. We estimate the model using simulated method of moments and multiple waves of the China Health and Nutrition Survey, a household-level survey containing data on the occupation, education, and income of all household members.

The estimated model provides three key pieces of information which we employ in our growth accounting exercise. These include sector-specific returns to education, the extent to which education increases an individual's probability of working in the nonagricultural sector, and the productivity gain associated with having a nonagricultural job. Note that the latter two effects of education depend upon an individual worker's characteristics and ability. For example, the marginal benefit of education in terms of lowering the cost of working in the nonagricultural sector can be negligible for a worker born in an urban area, where nonagricultural jobs are abundant, but can be substantial for a worker who must migrate to improve his chances of finding a nonagricultural job.

To quantify education's within-sector contribution to growth, we first combine the estimated sector-specific returns to education with measures of educational attainment to calculate the growth of human capital in each sector. The underlying assumption, following Young (2003), is that relative incomes of individuals within a sector reflect their relative marginal products. This assumption is consistent with the presence of the aforementioned labor market barriers if those barriers only impede workers' mobility across sectors but workers can move freely between competitive firms within each sector. We then weight each sector's human capital growth by the sector's share of aggregate output to compute the contribution of education to aggregate growth through increased human capital.

Turning to education's contribution to growth due to labor reallocation, we multiply our individual-specific measure of education's impact on the likelihood of working in the nonagricultural sector by the expected productivity differential between a nonagricultural and agricultural job. Note that the differential is predicted using our estimated income processes and individual characteristics. We then average this product over all educated workers to get a measure of the average productivity gain from reallocation due to education. 
Finally, we multiply this average by the change in the fraction of educated workers to get the contribution to aggregate growth.

Our main findings are that (a) education accounts for a large fraction of the productivity growth associated with labor reallocation and (b) education's contribution to growth through labor reallocation is at least as large as its contribution through raising human capital within sectors. For example, comparing our baseline results to the growth decomposition of Brandt, Hsieh and Zhu (2008), increased educational attainment accounts for over one-third of the growth attributable to labor reallocation in China from 1978 to 2004. Moreover, roughly 11 percent of the overall growth in output per worker is accounted for by increased education, with 9 percent coming through the labor reallocation channel and 2 percent being accounted for by education's role in increasing human capital. Our main qualitative findings are robust to a number of different robustness checks. Evidently, to fully understand education's impact on economic growth in China, it is important to consider education's role in facilitating labor reallocation.

These findings suggest that education policy may be a useful tool for achieving a more efficient allocation of labor in China. Although the Chinese government could reduce labor market barriers directly by eliminating internal migration restrictions, this may not be desirable given concerns about the ability of urban areas to accommodate massive labor inflows. On the other hand, because migration regulations are less restrictive for educated workers, policies that reduce the cost of education can facilitate a gradual reduction in the effective restrictiveness of the regulations, even if the regulations themselves do not change. Note that the Chinese government has worked to reduce the (private) cost of education over the years by introducing free compulsory education systems and school-building programs (Pepper 1996 and Hannum 1999).

Our paper is related to several strands of research in development and labor economics. Our emphasis on education as a driving force of structural transformation draws from the insights of Caselli and Coleman (2001). They build a model in which declining education costs allow an increasing proportion of the labor force to become educated and work in the nonagricultural sector and use their model to explain features of the U.S. structural transformation. As for China's more recent structural transformation, Brandt et al. (2008) and Dekle and Vandenbroucke (2006) have quantified the importance of labor reallocation for growth but have not focused on the role of education per se. All three studies take a "topdown" approach by calibrating structural models to aggregate data and then conducting 
counterfactual experiments to gauge the importance of various driving forces for reallocation and growth ${ }^{3}$ In this paper, we do not attempt to cover the same breadth of driving forces as the top-down approach, but instead take a "bottom-up" approach, which allows for a careful quantitative investigation of education's impact on labor reallocation built on micro-level estimates of its effects.

Our work is also motivated by studies of the importance of the efficient allocation of inputs for understanding both within-country growth and income differences across countries. For example, Hsieh and Klenow (forthcoming) use micro data on manufacturing establishments to calculate potential productivity gains in China and India that could result from an improved allocation of capital and labor.$^{4}$ Looking at a broader set of countries, Restuccia, Yang and Zhu (2008) and Vollrath (2009) emphasize the depressing effect an inefficient sectoral allocation of inputs (i.e., too many inputs in the lower-productivity agricultural sector) has on aggregate output and total factor productivity. These empirical studies present general measures of the potential gain from better allocations but do not focus on providing measures of how potential policies might improve efficiency. Our finding that education helps individuals overcome labor market barriers has implications for policies aimed at facilitating labor reallocation, even for countries without explicit migration barriers like China. As long as returns to education are sufficiently higher in higher-productivity sectors $5_{5}^{5}$ a government subsidy which reduces the cost of education can induce workers to increase their educational attainment and move into these sectors.

Finally, our work is closely related to micro-level empirical studies on the relationship between education and income. Our empirical model and specification draws from many papers including Mincer (1974) for modelling education's impact on earnings, Roy (1951) for determining sector choice given a worker's unobserved sector-specific ability, and Willis and Rosen (1979) and Heckman and Honore (1990) for specifying the choice of education as a function of a worker's unobserved ability. Our contributions to this literature include providing a new estimate of returns to education in China by controlling for a worker's

\footnotetext{
3 "Aggregate" data refers to national- or sector-level data, in contrast to the micro-level (household) data we use. Driving forces considered by the Chinese studies include sectoral total factor productivity growth, increases in the rate of fixed investment, changes in the size of the public sector, and labor market barriers, but education is not modelled explicitly.

${ }^{4}$ See Bergoeing, Kehoe, Kehoe, and Soto (2002), Bartelsman, Haltiwanger, and Scarpetta (2008), and Alfaro, Charlton, and Kanczuk (2008) for similar empirical evidence on the importance of resource misallocation in other countries.

${ }^{5}$ For example, Schultz (1971) reports that returns to education appear to be higher in urban areas (with higher-wage jobs) than in rural areas for Colombia.
} 
choice of both education and sector, and ultimately linking these estimates with changes in the aggregate distribution of worker characteristics to better understand China's economic growth.

The rest of the paper proceeds as follows. In Section 2, we describe a two-sector growth accounting framework and establish which key variables we need to estimate from microlevel data to account for education's impact on growth. Section 3 describes the data and discusses why increased educational attainment was likely an important driving force of labor reallocation in China. In Section 4, we present our empirical model and report baseline estimates of the effects of education on reallocation and growth. Section 5 presents the results of various robustness checks and discusses how our approach relates to others in the growth accounting literature. Section 6 concludes.

\section{Growth Accounting Framework}

We begin by presenting a growth accounting framework for an economy with two sectors, agriculture $(a)$ and non-agriculture $(n)$, in which there are barriers to labor mobility between sectors. As a result, wages (assumed to equal marginal products of labor) are not necessarily equated across sectors. We will consider the contribution of increased educational attainment to growth in this economy. Education affects growth through increasing the human capital of workers - possibly at different rates in each sector - and also through lowering the cost of mobility, thus enabling workers to move into the higher-productivity sector.

We assume sectoral value production functions of the form

$$
Y_{s t}=p_{s t}\left(A_{s t} H_{s t}\right)^{\alpha_{s}} K_{s t}^{1-\alpha_{s}}
$$

where $\alpha_{s}$ denotes the labor share in sector $s, K_{s t}$ denotes physical capital, $H_{s t}$ denotes the amount of human-capital-augmented labor, and $A_{s t}$ is a measure of total factor productivity. The inclusion of $p_{s t}$, the price of the sector $s$ good relative to the aggregate price level, means $Y_{s t}$ denotes a value product rather than the quantity of goods produced. It also allows us to simply express aggregate output $Y_{t}$ as

$$
Y_{t}=Y_{a t}+Y_{n t} .
$$


We follow the growth accounting literature by decomposing aggregate labor productivity (i.e., output per worker) growth into within-sector productivity growth and growth resulting from reallocation of labor between sectors. Specifically, let $y_{a t}, y_{n t}$, and $y_{t}$ denote output per worker in agriculture, non-agriculture, and the aggregate, respectively, and $l_{a t}$ and $l_{n t}$ denote agricultural and nonagricultural shares of total employment, so $l_{a t}+l_{n t}=1$. Aggregate output per worker can then be expressed as the weighted average of output per worker in each sector

$$
y_{t}=y_{a t} l_{a t}+y_{n t} l_{n t}
$$

and aggregate labor productivity growth is given by

$$
d \ln y_{t}=\frac{y_{a t} l_{a t}}{y_{t}} d \ln y_{a t}+\frac{y_{n t} l_{n t}}{y_{t}} d \ln y_{n t}+\frac{\left(y_{n t}-y_{a t}\right)}{y_{t}} d l_{n t}
$$

Equation (1) shows three channels through which increased education can account for growth in output per worker: (1) growth in agricultural labor productivity $d \ln y_{a t}$, (2) growth in nonagricultural labor productivity $d \ln y_{n t}$, and (3) labor reallocation $d l_{n t}$.

Let's first consider how to construct the within-sector productivity growth attributable to increased education. The production function can be rewritten in terms of output per worker and human capital per worker, $h_{s t}$, as

$$
y_{s t}=p_{s t}^{\frac{1}{\alpha_{s}}} A_{s t} h_{s t}\left(\frac{K_{s t}}{Y_{s t}}\right)^{\frac{1-\alpha_{s}}{\alpha_{s}}}
$$

Decomposing output per worker in terms of the capital-output ratio rather than the capitallabor ratio is useful because it accounts for both the direct impact of increased human capital on output per worker and the potential indirect impact through raising physical capital per worker (see, for example, Klenow and Rodriquez-Clare (1997) for further discussion). As a result, in our accounting, the growth rate of human capital per worker has a one-for-one impact on the growth rate of output per worker:

$$
d \ln y_{s t}=d \ln h_{s t}+\frac{1}{\alpha_{s}} d \ln p_{s t}+d \ln A_{s t}+\frac{1-\alpha_{s}}{\alpha_{s}} d \ln \left(\frac{K_{s t}}{Y_{s t}}\right)
$$

To construct sectoral measures of the growth in human capital per worker due to educational attainment, we follow Young (2003) and assume human capital is a constant returns to scale function of differentiated labor types: in our baseline case, educated $(e d u)$ and 
uneducated (uned). Human capital growth may then be expressed as

$$
d \ln h_{s t}=\beta_{s t} d \ln l_{s t}^{\text {uned }}+\left(1-\beta_{s t}\right) d \ln l_{s t}^{e d u},
$$

where $l_{s t}^{u n e d}\left(l_{s t}^{e d u}\right)$ denotes the fraction of uneducated (educated) workers in sector $s$ at time $t$, and $\beta_{s t}$ is the share of sectoral wages paid to uneducated workers:

$$
\beta_{s t} \equiv \frac{w_{s t}^{\text {uned }} l_{s t}^{u n e d}}{w_{s t}^{\text {uned }} l_{s t}^{\text {uned }}+w_{s t}^{\text {edu }} l_{s t}^{\text {edu }}}=\frac{l_{s t}^{\text {uned }} / l_{s t}^{\text {edu }}}{l_{s t}^{\text {uned }} / l_{s t}^{\text {edu }}+\exp \left(\gamma_{s t}\right)},
$$

where $\gamma_{s t} \equiv \ln \left(w_{s t}^{e d u}\right)-\ln \left(w_{s t}^{u n e d}\right)$ denotes sectoral returns to education. To convert our estimates of returns to education into measures of human capital, we are assuming that relative incomes of individuals within a sector reflect their relative marginal products. This assumption is consistent with the presence of labor market barriers as workers can be paid their marginal product and, at the same time, not necessarily be working in the sector in which they would be most productive. In summary, to compute education's contribution to within-sector human capital growth, it is sufficient to have returns to education $\left(\gamma_{s t}\right)$ and the shares of educated and uneducated workers $\left(l_{s t}^{\text {edu }}, l_{s t}^{\text {uned }}\right)$ in each sector.

Turning to labor productivity growth due to labor reallocation, first note that in the absence of labor market barriers and under the assumption that both sectors have the same labor share, sectoral (average) labor productivities would be equated and reallocation would make no contribution to aggregate labor productivity growth ${ }^{6}$ In the presence of labor market barriers, however, labor reallocation from low- to high- productivity sectors can generate sizeable growth in aggregate productivity. Isolating the portion of this growth that comes from increased educational attainment requires two measures: the change in the nonagricultural share of employment due to education and the associated productivity gain.

Suppose that the nonagricultural sector's share of total employment $\left(l_{n t}\right)$ is a function of the share of educated workers in the labor force $\left(l_{t}^{e d u}\right)$ and other factors $\left(X_{t}\right)$. Education can affect the nonagricultural employment share through various channels such as reducing the barriers to working in non-agriculture and, to the extent returns to education are higher in non-agriculture, making workers more likely to choose a nonagricultural job. We can write

$$
d l_{n t}=\frac{\partial l_{n t}}{\partial l_{t}^{e d u}} d l_{t}^{e d u}+\frac{\partial l_{n t}}{\partial X_{t}} d X_{t},
$$

\footnotetext{
${ }^{6}$ The absence of labor market barriers implies marginal products are equated across sectors and technologies with identical factor shares implies the ratio of average products in the two sectors is equal to the ratio of marginal products.
} 
and want to measure the first term on the right side. Using micro-level data, we can construct the effect of education on sector choice as follows

$$
\frac{\partial l_{n t}}{\partial l_{t}^{e d u}}=\int\left[P_{n t}^{e d u}(i)-P_{n t}^{u n e d}(i)\right] d F_{t}^{e d u}(i)
$$

where $i$ denotes a worker's type (based on observable characteristics such as education, gender, etc. $), P_{n t}^{E}(i)$ is an individual/time-specific probability of working in the nonagricultural sector conditional on education status $E$, and $F_{t}^{e d u}$ is the cumulative density of educated workers' types. That is, education's impact on sector choice is given by the average (across educated workers) change in the probability of working in the nonagricultural sector that results from obtaining education. Multiplying this measure by the change in the fraction of educated workers, $d l_{t}^{e d u}$, produces the change in the nonagricultural employment share due to education.

To construct the contribution to aggregate productivity growth, we must weight education's impact on the nonagricultural employment share by the productivity gain associated with reallocation. From the third term of Equation (1), one might consider simply weighting by the difference in average productivity in the two sectors: $\frac{\left(y_{n t}-y_{a t}\right)}{y_{t}} \frac{\partial l_{n t}}{\partial l_{t}^{e d u}} d l_{t}^{e d u}$. The problem with this weighting, however, is that it does not adequately isolate the productivity gain due solely to reallocation. Instead, we construct individual-specific measures of the productivity gain as the difference between being an uneducated nonagricultural worker and an uneducated agricultural worker.7 We also account for the possibility that the productivity gain may be correlated with the individual-specific change in the probability of working in the nonagricultural sector that results from obtaining education. Thus, our measure of education's contribution to productivity growth through reallocation is

$$
\left[\int \frac{\left[y_{n t}^{\text {uned }}(i)-y_{a t}^{\text {uned }}(i)\right]\left[P_{n t}^{e d u}(i)-P_{n t}^{u n e d}(i)\right]}{y_{t}} d F_{t}^{e d u}(i)\right] d l_{t}^{e d u}
$$

In Section 4, we show how alternative measures that ignore the aforementioned correlation or rely on aggregate measures of productivity affect our results.

\footnotetext{
${ }^{7}$ This measure is based on the following decomposition. Expected income $Y$ conditional on education level $E$ is $\mathbb{E}(Y \mid E)=\operatorname{Pr}(s=n \mid E) \times \mathbb{E}\left(Y_{n}^{E}\right)+\operatorname{Pr}(s=a \mid E) \times \mathbb{E}\left(Y_{a}^{E}\right)$. The difference in expected income between an educated $(e d u)$ and uneducated (uned) worker can then be written as $\mathbb{E}(Y \mid e d u)-\mathbb{E}(Y \mid u n e d)=$ $\operatorname{Pr}(n \mid e d u) \times\left[\mathbb{E}\left(Y_{n}^{e d u}\right)-\mathbb{E}\left(Y_{n}^{\text {uned }}\right)\right]+\operatorname{Pr}(a \mid e d u) \times\left[\mathbb{E}\left(Y_{a}^{\text {edu }}\right)-\mathbb{E}\left(Y_{a}^{\text {uned }}\right)\right]+[\operatorname{Pr}(n \mid e d u)-\operatorname{Pr}(n \mid$ uned $)] \times$ $\left[\mathbb{E}\left(Y_{n}^{\text {uned }}\right)-\mathbb{E}\left(Y_{a}^{\text {uned }}\right)\right]$. The first two terms reflect gains from education within a sector, while the third term consists of gains from a change in the probability of working in the nonagricultural sector.
} 
To recap, the key message of this section is that sector-specific returns to education $\left(\gamma_{s t}\right)$ and individual-specific measures of education's impact on the likelihood $\left(P_{n t}^{\text {edu }}(i)-P_{n t}^{\text {uned }}(i)\right)$ and productivity gain $\left(\frac{y_{n t}^{\text {uned }}(i)-y_{a t}^{\text {uned }}(i)}{y_{t}}\right)$ from working in the nonagricultural sector are needed to compute the contribution of education to labor productivity growth in a two-sector economy with barriers to labor mobility across sectors. In subsequent sections, we describe how the Chinese economy fits into the framework we have described, use micro-level data from China to estimate these measures, and then decompose the contribution of education to growth into the within- and between-sector channels.

\section{Data and Institutional Background}

\subsection{China Health and Nutrition Survey}

Quantifying education's role in accounting for both labor reallocation between the agricultural and nonagricultural sectors and increased human capital within sectors requires micro-level data with detailed information about the income, education and sector of workers. We use data from the China Health and Nutrition Survey (CHNS) 8 an unbalanced panel household survey with refreshment that contains this key information along with other socioeconomic variables for each household member. It surveys the nine Chinese provinces shown in Figure 1: Guangxi, Guizhou, Heilongjiang, Henan, Hubei, Hunan, Jiangsu, Liaoning, and Shandong. We use six waves of the CHNS, ranging from 1989 to 2004, which allows us to also analyze time trends and recent changes in the Chinese labor market.

The main advantages of the CHNS relative to other publicly-available data sets are that it includes data on both rural and urban areas and that it has several, including recent, survey years $9^{9}$ One concern that arises, given our aggregate focus, is whether the nine provinces are representative of China as a whole on the dimensions most crucial to our analysis, which include educational attainment, the sectoral decomposition of workers, and the income differential between agricultural and nonagricultural jobs. To allay this concern,

\footnotetext{
${ }^{8}$ The CHNS is jointly conducted by the Carolina Population Center at the University of North Carolina at Chapel Hill and the National Institute of Nutrition and Food Safety at the Chinese Center for Disease Control and Prevention. More detailed information about the CHNS can be found at the CPC UNC website: http://www.cpc.unc.edu/projects/china

${ }^{9}$ The Chinese Household Income Project survey is another publicly-available Chinese household income data set, but only its 1988 and 1995 vintages are publicly available. The National Bureau of Statistics of China conducts household surveys in both rural and urban areas, but only the urban surveys are publicly available.
} 


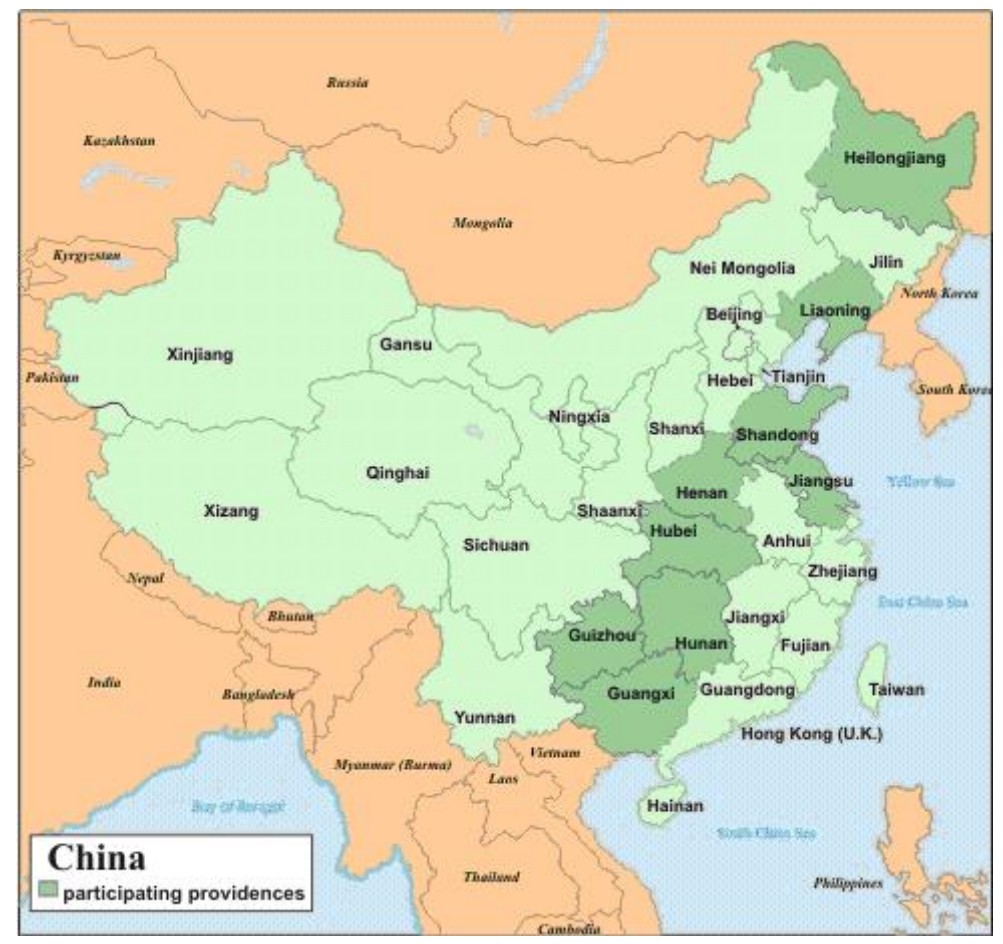

Figure 1: Map of Surveyed Provinces

in Table 1 we compare summary statistics from the multiple waves of the CHNS (first panel) to those from national surveys - specifically, the census and China Statistical Yearbooks (CSYs) (second panel). Because the census only occurs every five years (1990, 1995, 2000, and 2005), Table 1 entries that rely on census data are reported for the year closest to the census survey year. In addition, for comparison with the CHNS, we construct annual statistics by fitting a second-order polynomial time trend to the census data.

Comparison of the two panels of Table 1 shows that the CHNS oversamples workers in the nonagricultural sector in early waves of the survey and undersamples them in later years. Therefore, in each survey year, we weight the CHNS sample so that sectors have the same weights as in the national surveys. The share of workers completing middle school (a proxy for educational attainment) in our weighted sample remains roughly in line with census data.

For the income statistics, although the CSYs do not provide a breakdown of income by sector, household income per capita is reported by rural and urban areas and we will use this decomposition for our comparison. Because 75 percent of nonagricultural workers live in urban areas and 86 percent of agricultural workers live in rural areas, the comparison of urban-rural income differentials probably gives a good picture of the nonagriculturalagricultural income differentials. Appendix A provides a detailed description of our income 
measures, and Table 1 displays annual income per household member by area in the CHNS. The income differential in the CHNS is slightly smaller than that in the CSY in most years, although the discrepancy increases in 2000 and 2004. A partial explanation of the discrepancy is that we use gross annual income measures for agricultural workers in the CHNS, whereas the CSY measures correspond to net total income. We did not use net income for agricultural workers because subtracting reported expenses from gross revenues led to negative reported net income for some households, which apparently is somewhat of a common problem with survey data on revenues and expenses (de Mel, McKenzie, and Woodruff 2007). In our view, using gross incomes for agriculture workers is a better choice. The main implication is that we will find a smaller benefit from labor reallocation out of the agricultural sector, but this works against our main finding that education has a large impact through the labor reallocation channel.

Next, we examine whether the CHNS data exhibits reasonable income patterns across educated and uneducated workers, which are important for our estimates of returns to education in Section 4. To do so, we regress income on education measures (and other control variables) and compare the coefficients to related studies. The first four columns of Table 2 contain results from regressing the log of per capita household income on household head characteristics. Regressions of this type are often used in the agricultural sector in the absence of individual income data, but they have also been run for nonagricultural workers. We find that one additional year of schooling for an agricultural (nonagricultural) household head is associated with a 0.02 (0.05) percent increase in income per household member, consistent with findings from a number of studies (e.g., Meng and Wu (1994), Li and Zhang (1998), Benjamin et al. (2000), and Yang and An (2002)). The regressions in columns (2) and (4) replace years of schooling with a dummy variable for whether the household head completed middle school. We postpone discussion of these results until Section 5, where we compare them to our main results, which report individual-level returns to education. The final column in Table 2 follows Young (2003) by regressing the average labor incomes of (sex $\mathrm{x}$ age $\mathrm{x}$ education) groups on appropriate dummies. We find returns to education similar to his estimates (although a bit higher for tertiary education).

\subsection{Education and Barriers to Labor Mobility}

Previous studies have documented the sizeable contribution of labor reallocation to China's recent growth (Brandt et al. 2008 and Dekle and Vandenbroucke 2006). Although many 
factors undoubtedly played a part in driving the reallocation, we have chosen to focus our efforts on quantifying the impact of one factor: increased educational attainment. One might wonder, "why is education a likely suspect for explaining the movement of workers into the nonagricultural sector?" In this subsection, we document Chinese migration regulations that created barriers to working in non-agriculture. We then argue that educated workers were more likely to overcome these restrictions and present evidence consistent with this hypothesis. If our hypothesis is correct, then from a macro perspective, increased education could have played a major role in making the allocation of labor more efficient.

\subsubsection{Chinese Migration Regulations}

Throughout our sample period, rural residents formed the majority of the Chinese population, ranging between 82 percent in 1978 and 57 percent in 2005, while most of the nonagricultural jobs could be found in urban areas. As a result, rural-to-urban migration was often necessary for a Chinese worker to obtain a nonagricultural job. A review of Chinese internal migration policy suggests that barriers to migration existed during the past three decades and were larger for uneducated individuals.

Migration from rural to urban areas is regulated primarily by China's household registration system, called the hukou system. Just as foreigners must acquire a working visa to legally work in many countries, rural Chinese residents should obtain a permit to work in urban areas. There are three types of permits: temporary residence permits lasting three to six months, medium-term permits (blue-stamped hukous) and permanent urban hukous. To obtain a medium-term permit or permanent urban hukou, an applicant must satisfy certain restrictive qualification criteria, largely based on wealth and education, and pay an urban entry fee set by the respective local government.10 Thus, education affects the ability to migrate in two ways: directly through the qualification criteria and indirectly by reducing the real cost (in terms of hours worked) of the urban entry fee.

Despite changes to the hukou system that have made rural-to-migration easier, obtaining either a medium-term permit or permanent urban hukou has remained important for a rural migrant seeking employment.11 For example, a person without a local hukou needs special

\footnotetext{
${ }^{10}$ Urban entry fees vary by location, but to give some idea of their magnitude, the fee ranged from 10,000 to 40,000 Yuan in Shanghai in 1999 (Chan and Zhang 1999), which was 4.5 to 18.1 times the annual net income per rural household member in China in 1999.

${ }^{11}$ Chan and Zhang (1999), Wang (2004, 2005) and Chan and Buckingham(2008) provide detailed explanations of hukou reforms. Among recent reforms, a movement to remove agricultural and nonagricultural
} 
approval for her children to attend local primary or secondary school, and even with such approval, must pay additional fees that are often ten times the normal fees for attending primary or secondary school (Wang 2005).

\subsubsection{Empirical Evidence of Migration Barriers}

The previous subsection described regulations which, if followed, make it relatively easier for educated workers to migrate to urban areas and work in the nonagricultural sector. However, if most migrants have temporary permits or no permit at all, then education might not actually be empirically linked with migration. In what follows, we check whether there is in fact a relationship (i.e., positive correlation) between education and migration. To be clear, we are not trying to identify a causal effect of education on outcomes - that exercise will be undertaken in the next section - but rather we are simply looking for evidence consistent with our hypothesis that Chinese migration regulations have real effects that are larger for the less educated.

To examine this hypothesis, we run regressions of the form

$$
M(i)=\lambda_{0}+\lambda_{1} E(i)+\lambda_{2} X(i)+\epsilon(i),
$$

where $M(i)$ indicates whether worker $i$ has migrated, $E(i)$ is an indicator of the worker's education level, and $X(i)$ is a vector of other characteristics. If education does help workers to migrate and work in the nonagricultural sector, $\lambda_{1}$ will be positive. For these regressions, we use two measures of migration, inter-provincial migration and migration from anywhere (including intra-provincial migration). We also consider two different measures of education level, "completed middle school" and "completed high school". Other control variables, $X(i)$, include both individual characteristics (gender, race, birth-year fixed effects) and provincelevel controls, defined for the worker's birth province at the time the worker was 12 years old. The provincial controls include fixed effects and proxies for socioeconomic conditions which may affect the migration decision, such as the share of urban hukuo holders, the share of nonagricultural employment, and the share of the state sector.

classifications took place in 2001 but was suspended in mid-2002 due to lack of funding and an inability to accommodate new urban residents. Wang (2005) concludes that while hukou reforms since 1997 relaxed restrictions, most migrants are still unable to obtain a permanent urban hukou. Chan and Buckingham (2008) conclude, "The cumulative effect of these reforms (reported often in the newspapers in late 2005) is not abolition of the hukou but devolution of responsibility for hukou policies to local governments, which in many cases actually makes permanent migration of peasants to cities harder than before." 
The sample we use to estimate Equation (5) consists only of household heads because they are the only individuals for whom the CHNS provides migration status. We further restrict the sample to nonagricultural sector workers because the migration regulations restrict migration from rural to urban areas (i.e., into nonagricultural employment). Table 3 displays the results. Columns (1)-(2) are based on the "completed middle school" education measure, while columns (3)-(4) repeat these regressions using "completed high school". The odd-numbered columns present results for all migrants, while the even columns focus on between-province migrants. We also experimented with various combinations of the provincial controls (not shown in Table 3) but found that, regardless of the specification, educated workers in the nonagricultural sector are more likely to be migrants than uneducated workers, especially if they have completed high school.

One caveat concerning the applicability of these results to the entire Chinese population is that the CHNS may not representatively sample individuals based on their hukou status. That is, if migrants with temporary permits or no permit at all are under-represented in the CHNS, our finding above could simply reflect the effect of education on obtaining a medium-term or permanent permit 12 Although this could possibly drive the results above, other pieces of evidence increase our confidence that educated workers are, in fact, more likely to migrate.

First are the results of studies based on household surveys which contain information on household members that have migrated to another location. Using data for the Changping county of suburban Beijing from 1979-1988, Zhao (1997) found that schooling played an important role in raising the probability of rural-to-urban migration. De Brauw and Giles (2008) use data collected from four provinces (Shanxi, Jiangsu, Anhui, and Henan) from 1986 to 2003. They exploit policy changes which made it easier for rural migrants to obtain a temporary permit and find that relaxed migration barriers lead to reduced educational attainment for rural migrants. One interpretation of this finding is that because temporary permits do not include education as a qualification criteria, making temporary permits easier to obtain leads to a reduction in migration costs especially for the uneducated. Education's role in reducing the cost of migration is thus weakened, and educational attainment may decrease.

\footnotetext{
${ }^{12}$ We cannot directly check whether the distribution of hukou holders in the CHNS represents the population distribution because there are no good official statistics for checking the number and characteristics of illegal/temporary migrants. We would not only need to know the number of urban and rural hukou holders but also where they actually reside.
} 
Second, previewing some of the results reported in the next section, we find that the income difference between working in the nonagricultural and agricultural sector is greater for educated workers. Because educated workers have more to gain from working in the nonagricultural sector, they have a greater incentive to migrate in search of these jobs.

\section{Empirical Framework and Results}

In this section we develop and estimate a tractable model to quantify the effect of education on workers' sector choice, their earnings within each sector, and their total productivity gains from education. The key variables of interest are sector-specific returns to education $\left(\gamma_{s}\right)$, education's impact on the probability of working in the nonagricultural sector $\left(P_{n t}^{e d u}(i)-P_{n t}^{\text {uned }}(i)\right)$ and the associated productivity gain $\left(\frac{y_{n t}^{\text {uned }}(i)-y_{a t}^{\text {uned }}(i)}{y_{t}}\right)$. We then use these estimates to construct measures of education's contribution to labor reallocation and economic growth.

\subsection{The Model}

We specify a model in which individuals choose their level of education and the sector in which they work to maximize the expected net present discounted value (PDV) of their lifetime income. We assume that individuals first decide whether to obtain an education $(E \in\{0,1\})$, then choose to work in the agricultural or nonagricultural sector $(s \in\{a, n\})$, and finally enter the work force, remaining in the same sector until retirement.

We denote $V_{s}^{E}(i)$ as the expected PDV of lifetime income for individual $i$ with education level $E$ who works in sector $s$

$$
V_{s}^{E}(i)=\mathbb{E}\left(\sum_{t=t_{E}+b}^{T+b} \rho^{t-\left(t_{0}+b\right)} Y_{s, t}^{E}(i)\right)
$$

where $t$ denotes calendar year, $b$ denotes $i$ 's birth year, $t_{E}$ is the age at which $i$ starts work conditional on having education level $E, T$ denotes retirement age, $\rho$ is the discount factor, and $Y_{s, t}^{E}(i)$ is individual $i$ 's earnings at time $t$. Following the literature started by Roy (1951) and Mincer (1974), we posit that individual earnings take the form

$$
Y_{s, t}^{E}(i)=\exp \left(\alpha_{s}+\beta_{s} X_{t}(i)+\gamma_{s} E(i)+\mu_{s}(i)+\epsilon_{s, t}(i)\right)
$$


That is, earnings of individual $i$ at time $t$ depend on her educational attainment $E(i)$, other observable characteristics $X_{t}(i)$, her individual-sector-specific productivity $\mu_{s}(i)$ which is not observed by researchers, and random shocks $\epsilon_{s, t}(i)$. We assume that the unobserved heterogeneity and the random shocks are independent of each other and are drawn from iid normal distributions with mean zero and variances $\sigma_{\mu, s}^{2}$ and $\sigma_{\epsilon, s}^{2}$, respectively.

An individual's choice of education and sector will maximize her discounted earnings net of the costs associated with the schooling and sector choice. We denote $C_{n}^{E}(i)$ as the cost of working in the nonagricultural sector (relative to the agricultural sector) for an individual with education level $E$

$$
C_{n}^{E}(i)=\widetilde{\theta} Z(i)+\widetilde{\delta} E(i)+\widetilde{\eta}(i)
$$

where $Z(i)$ are some observable characteristics and $\widetilde{\eta}(i)$ is a normal random variable with mean zero and variance $\sigma_{\eta}^{2}$. This cost function is meant to capture barriers to labor mobility between sectors, such as the migration regulations, and we allow for the possibility that education can alter these costs. In particular, if the cost of working in the nonagricultural sector is relatively low for the educated, $\widetilde{\delta}$ will be negative. In addition, let $C_{\text {edu }}(i)$ denote the cost of education for individual $i$

$$
C_{e d u}(i)=\widetilde{\kappa} W(i)+\widetilde{\nu}(i)
$$

where $W(i)$ are some observable characteristics and $\widetilde{\nu}(i)$ is a normal random variable with mean zero and variance $\sigma_{\nu}^{2}$.

For a given educational attainment, individual $i$ will choose to work in the nonagricultural sector if and only if the difference between the expected PDV of lifetime income in the nonagricultural and agricultural sector is greater than the cost of working in non-agriculture

$$
\frac{\left[V_{n}^{E}(i)-V_{a}^{E}(i)\right]}{\sigma_{\eta}}>\theta Z(i)+\delta E(i)+\eta(i),
$$

where $\theta \equiv \widetilde{\theta} / \sigma_{\eta}$, etc. Moving to education choice, we can express an individual's expected net $\mathrm{PDV}$ of lifetime income conditional on education as

$$
V^{E}(i)=\left(V_{n}^{E}(i)-C_{n}^{E}(i)\right) \operatorname{Pr}[s=n \mid E(i)]+V_{a}^{E}(i) \operatorname{Pr}[s=a \mid E(i)] .
$$

Individual $i$ obtains education if and only if the difference between the expected PDV of net lifetime income with education and that without education is greater than the cost of 
education:

$$
\frac{\left[V^{1}(i)-V^{0}(i)\right]}{\sigma_{\nu}}>\kappa W_{i}+\nu(i), \text { where } \kappa=\frac{\widetilde{\kappa}}{\sigma_{\nu}} \& \nu(i)=\frac{\widetilde{\nu}(i)}{\sigma_{\nu}} .
$$

We now describe our baseline specification of Equations (6) - (8), postponing discussion of alternative specifications until Section 5. We exclude individuals who change education or sector from the sample for our baseline analysis but will include these observations in a subsequent robustness exercise.

(i) Income process: Education $E(i)$ is a dummy variable taking a value of 1 if the individual completes middle school. Other worker characteristics $X_{t}(i)$ which affect earnings include gender, race, marital status, age, age squared, dummies for provinces, and linear province-specific time trends where year 1989 is normalized to zero. The estimated income processes, one for each sector, allow us to predict a worker's expected income over time. Then, to calculate the worker's predicted present discounted value of lifetime income, we assume a discount rate of 0.95 , that workers choose whether to attend middle school at age 12 , that they enter the labor force at age 15 if educated and age 12 otherwise, and that they retire at age 65 .

(ii) Sector choice: The cost of working in the nonagricultural sector is a function of characteristics $Z(i)$ : gender, race, dummies for birth groups, dummies for provinces, and province-level employment shares of the state and nonagricultural sector. Birth groups are defined as workers born in (1) 1947 or earlier, (2) from 1948 to 1955, (3) from 1956 to 1965 and (4) 1966 or later. Workers in the fourth birth group made their education and sector choice in or after 1978, the beginning of the Open Door policy reforms. The other dates were chosen to equally divide the remaining cohorts into three groups. We use dummies for birth groups to control for cohort effects but also consider a more flexible form of accounting for such effects in our alternative specifications. The final two variables, the province-level employment share of the state and nonagricultural sector, are for the individual's original province at the time she makes her education/sector choice (age 12). We include the nonagricultural employment share because workers from provinces with a large supply of nonagricultural sector jobs likely face a lower cost of working in that sector. The state sector employment share is included because provinces with large state sectors may be particularly slow to respond to the rapid expansion of nonagricultural jobs, and thus, workers in these provinces likely face higher costs of working in the nonagricultural sector.

(iii) Education choice: Variables $W(i)$ which affect the cost of education include gender, 
race, dummies for provinces, dummies for birth groups, and the number of students enrolled in secondary school, which is constructed for the individual's original province at the time she was age 12. Higher enrollment may proxy for lower schooling costs or positive peer pressure to attend school.

(iv) Attrition: Finally, we also assume that the distribution of unobserved heterogeneity in the CHNS sample remains the same as the population distribution, assumed to be normal $\left(0, \sigma_{\mu, s}^{2}\right)$. This implies that either worker attrition from our sample was random in terms of unobserved sector-specific ability or that these workers were replaced by workers with, on average, the same ability.

Our model specification obviously invokes some restrictive assumptions, such as assuming that workers make their education and sector choice just once, specifying educational attainment as a binary variable (as opposed to allowing for multiple levels), and assuming random attrition in terms of unobservable sector-specific abilities. The main reason we employ these rather simple assumptions is because of data limitations that would make it difficult to get identification in a more general model.

Specifically, regarding our assumptions on education and sector choice, although the CHNS panel covers a fairly long time period (1989 - 2004), less than 18 percent of workers ever change sector or education status. This reflects the fact that over 87 percent of workers were older than 22 (i.e., above schooling age) when they entered the survey, and the average time span for a surveyed individual is only 4.5 years. Moreover, the survey does not provide information on workers' employment histories nor the timing of their school attendance. Given these data limitations, estimating a more general model would require additional assumptions which would likely raise as many concerns as our current assumptions. However, although we do not attempt to estimate a more complicated model, we do undertake some robustness checks in Section 5 to partially address the concerns regarding education and sector choice.

We make our assumption of random attrition for two reasons. First, some attrition appears to be generated by technical issues regarding survey design as opposed to workers' choices. For example, households in Liaoning province were sampled in 1989 and 1991, but not in 1993 and 1997. Second, our data provides little information about why workers leave the sample and where they go, and thus, we cannot estimate a worker's decision to leave without relying on additional assumptions regarding the worker's outside options for 
residential choice 13

A detailed explanation of the identification of model parameters and our estimation method (simulated method of moments) is relegated to Appendix B, but we did think our procedure for estimating the income process of individuals in the agricultural sector deserved some explanation here. A challenge arises because the majority of workers in the agricultural sector are self-employed and multiple household members often work in the family farm. In other words, we observe household-level rather than individual-level income for much of the agricultural sector. To estimate individual-specific parameters using the householdlevel data, we aggregate the individual income processes within households and assume all household members receive the same random shocks. That is, for household $h_{j}$ :

$$
\ln \left(\sum_{i \in h_{j}} Y_{s, t}^{E}(i)\right)=\ln \left(\sum_{i \in h_{j}} \exp \left(\alpha_{s}+\beta_{s} X_{t}(i)+\gamma_{s} E(i)+\mu_{s}(i)\right)\right)+\epsilon_{s, t}\left(h_{j}\right)
$$

where $\epsilon_{s, t}(i)=\epsilon_{s, t}\left(h_{j}\right)$ for all $i \in h_{j}$. Thus, the identification of the agricultural sector income process comes from variation in the composition of agricultural households.

\subsection{Estimates from Micro-level Data}

Tables 4 and 5 contain the estimated income processes for the agricultural and nonagricultural sectors, with results for the baseline specification reported in column (1). We estimate returns to education of 10.1 percent in the agricultural sector and 14.2 percent in the nonagricultural sector. One interpretation of these findings is that formal education produces human capital which is more useful in nonagricultural production.

Although the estimated returns to education in the agricultural sector are not statistically significant at the conventional level, we do not think the lack of statistical power necessarily implies no returns to education. Because our model allows for correlated unobservable income shocks across time within a household (i.e., from the unobserved sector-specific ability), our "effective" number of observations is closer to the number of unique households (around 2,500) rather than the almost 8,000 household-survey-year observations reported in Table 4. When we do not allow for correlation of unobservable income shocks (see Section 5), the

\footnotetext{
${ }^{13}$ For example, one reason workers may leave the sample is that they choose to migrate to an unsurveyed area. To model a worker's choice of residency, we would need information on his choice set (i.e., possible residences and their characteristics, such as the type of job opportunities) and ultimate choice, which we do not have.
} 
estimated returns to education are somewhat smaller but statistically significant at the 5 percent level (column (2) of Table 4).

Table 6 shows the parameters governing sector choice. In our baseline specification in column (1), education decreases the cost of working in the nonagricultural sector and, for the marginal worker, raises the probability of working in the nonagricultural sector by more than 50 percent. Tables 7 and 8 show the rest of the results from our baseline model estimation, including parameters governing education choice (Table 7) and the shock processes (Table 8). Although we will not use these estimates for subsequent analysis, we note a few results: workers are more likely to obtain education the larger the difference between the expected PDVs with and without education $\left(V^{1}-V^{0}\right)$ and the smaller is the cost of education, which was proxied for by province-level school enrollment at the time individuals chose schooling. Finally, because all the equations in the baseline specification (column (1) of Tables 4-7) are simultaneously estimated, the model-fit statistics (i.e., sum of squared residuals) are reported just once, in Table 8.

\subsection{Education's Contribution to Economic Growth}

We can now assess the role of increased educational attainment in accounting for China's economic growth from 1978 to 2004 ${ }^{14}$ Education led to greater labor productivity in two ways: it increased human capital, and it facilitated the reallocation of labor from agricultural jobs to higher-productivity nonagricultural jobs. Our main finding is that the second channel was at least as important as the first in accounting for recent Chinese growth.

Table 9 shows the results of our calculations and compares them with other growth accounting exercises for China. The first panel of the table shows estimates of the growth in output per worker from various studies of the Chinese economy. For studies which considered multiple sectors of the economy, the second panel weights the sectoral growth rates by the sector's share of the economy to decompose aggregate growth according to Equation (1). Finally, the third panel displays our estimates of the contribution of education to aggregate growth through each term in Equation (1).

Our baseline estimates of agricultural and nonagricultural returns to education of 10.1 and 14.2 percent, respectively, imply within-sector annual growth in human capital per worker of 0.147 and 0.142 percent. Multiplying these estimates by the income share of each

\footnotetext{
${ }^{14}$ Please see Appendix $\mathrm{C}$ for a more detailed description of our calculations.
} 
sector, Table 9 (first row of third panel) shows that human-capital growth from increased education in agriculture (non-agriculture) accounts for 0.034 (0.107) percentage points of growth per year. That is, the direct effect of increased educational attainment on human capital accounts for about 2 percent (0.49 by agriculture and 1.54 by non-agriculture) of overall growth in Chinese output per worker from 1978 to 2004.

Turning to education's contribution to productivity through labor reallocation, we use our estimated income processes and sector choice equation to construct the productivity gain resulting from the increased probability educated individuals have of obtaining nonagricultural jobs. Column (4) of Table 9 contains results for our baseline measure - see Equation (4) - which we now describe in more detail. For each educated worker $i$, we construct the productivity difference between being an uneducated nonagricultural worker and an uneducated agricultural worker based on our estimated income processes. We then multiply this difference by the change in the individual-specific probability of working in the nonagricultural sector that results from attaining education. Note that the probability difference could be zero for some workers, meaning educational attainment has no impact on their sector choice. Finally, we calculate the average (across individuals) of this product for each of the six CHNS waves and then average over the six waves. We multiply our estimate of the average productivity gain by the growth in the share of educated workers, which averaged 1.11 percentage points per year from 1978 to 2004 .

The result is an increase in output per worker of 0.652 percentage points, which is just over 9 percent of the total growth in output per worker of 7.0 percent reported by Brandt et al. (2008). Thus, rising educational attainment accounts for 38 percent of the contribution of labor reallocation to Chinese economic growth. Moreover, it appears education's impact on economic growth through facilitating labor reallocation is relatively more important than its impact through increasing human capital (a combined 0.141 percentage points per year).

Columns (5)-(8) of Table 9 contain alternative measures of education's contribution to growth through labor reallocation that are based on different constructions of the productivity gain associated with moving into the nonagricultural sector. Our baseline measure took into the account that individuals who were more likely to work in the nonagricultural sector might also have higher productivity gains: $\int_{i}\left(y_{n}^{\text {uned }}(i)-y_{a}^{\text {uned }}(i)\right)\left(P_{n}^{e d u}(i)-P_{n}^{\text {uned }}(i)\right)$. If we do not allow for this interaction, $\int_{i}\left(y_{n}^{\text {uned }}(i)-y_{a}^{\text {uned }}(i)\right) \times \int_{i}\left(P_{n}^{e d u}(i)-P_{n}^{\text {uned }}(i)\right)$, column (5) (first row of third panel) shows our estimate of education's contribution to growth is slightly lower (0.636 vs 0.652 ). The measure in column (6) allows for the interaction but does not 
isolate the productivity gain due solely to reallocation. Specifically, it allows a change in education status in addition to the sector change, $y_{n}^{e d u}(i)-y_{a}^{u n e d}(i)$, and as expected, education's contribution through reallocation increases (to 0.761). Finally, columns (7) and (8) show the effect of simply using the average productivity difference between nonagricultural and agricultural, $y_{n}-y_{a}$, rather than controlling for individual characteristics. The measure in column (7) is based on average sectoral labor incomes from our CHNS sample, scaled by sectoral labor shares to produce measures of output per worker, while column (8) uses direct measures of output per worker from the CSYs. The difference between the measures based on alternative sources of aggregate data is small (0.896 vs. 0.862) compared to the difference between using aggregate and micro-level data (0.652). This clearly shows the importance of controlling for individual characteristics to isolate education's contribution to growth through reallocation.

\section{Robustness Checks}

In this section we examine the robustness of our growth accounting results. We first consider four alternative specifications of our empirical model and re-compute education's contribution through the within- and between-sector channels. We then make some back-of-theenvelope calculations to relate our approach to others from the growth accounting literature.

\subsection{Alternative Empirical Specifications}

\subsubsection{No Unobserved Heterogeneity}

Our first alternative specification omits the unobserved individual-sector-specific ability. Formally, we assume that $\mu_{s}(i)$ is drawn from a degenerate distribution, and thus, the error terms in the wage equation will be uncorrelated with the shocks affecting sector choice and education. This simpler model will produce biased estimates, but we think it is interesting to investigate the magnitude of the bias. Note that the sign of the bias is not clear ex-ante. For example, if high productivity workers face low costs of education and thus stay in school to signal their types to potential employers, then returns to education will be overestimated (ability bias). On the other hand, if the opportunity cost of schooling is high for extremely productive entrepreneurs, then returns to education will be underestimated (selection bias). 
Column (2) of Tables 4-7 show the resulting estimates under this specification.15 The returns to education are fairly similar to our baseline estimates in column (1), just a bit smaller for agriculture and somewhat larger for non-agriculture. The small differences are consistent with studies that find returns to education based on OLS regressions are quantitatively similar to those that control for the correlation between educational attainment and unobserved ability, either by using instrumental variables (e.g., Angrist and Krueger (1991)) or by focusing on identical twins (e.g., Ashenfelter and Rouse (1999)). Education's effect on sector choice is also similar to the baseline case (Table 6), and as a result, the growth accounting analysis without unobserved heterogeneity is quantitatively close to the baseline: rows (1) and (2) of the third panel of Table 9 show total contributions of education to growth of 0.793 and 0.798 percent per year, respectively.

Thus, the results without unobservable heterogeneity introduce only a small bias. At the same time, the computational intensity of the estimation procedure is greatly diminished because we can estimate the model equations sequentially, as described in Appendix B. We will therefore omit unobservable heterogeneity for the rest of our robustness checks to take advantage of the reduced computational burden.

\subsubsection{Time-varying Effects of Education}

We next allow for the possibility that education's impact on income and the cost of working in the nonagricultural sector may have changed over time. Specifically, we add interaction terms $E_{i} \times \tau$ to the income processes $(\tau=$ survey year $)$ and sector-choice equation $(\tau=$ birth-cohort dummy). We are particularly interested in whether education had a smaller impact on sector choice as migration restrictions were loosened over time. Column (3) of Table 6 shows only slight evidence of this. The coefficients on the interaction terms are positive, meaning that education led to a smaller decrease in the cost of working in the nonagricultural sector over time, but statistically insignificant. We also find that returns to education increase over time in both sectors. Turning to our growth accounting, the bottom line from Table 9 is that education's contribution to growth is a little smaller than in the previous specification (0.740 vs 0.798$)$, and the reallocation channel still accounts for most

\footnotetext{
${ }^{15}$ We also considered various alterations of our model specification but do not show these results as the estimates did not change much. These alterations included using different sets of control variables (e.g., adding year-squared and an education-year interaction term) for the income equations, not controlling for differences in the PDV of lifetime income in the sector and education choice equations, and using weighted OLS rather than weighted probit to estimate the sector and education choice equations.
} 
of the contribution.

\subsubsection{Changes of Education and Sector}

We also examine how our findings change when we include individuals who change their sector and educational attainment over time. 5.8 percent of workers in our sample increase their education from "not completed middle school" in an earlier survey to "middle school attainment or higher" in a later survey. ${ }^{16}$ In addition, 1,084 workers (12.6 percent of all workers) in our sample change sectors at some point. 600 workers move from agricultural to nonagricultural, 235 move the other direction, and the rest change sectors multiple times.

We include individuals whose status changes by using their latest reported educational attainment and sector as their education and sector throughout their survey participation. Although a simple way of including changers, this method will cause us to underestimate the contribution of education through reallocation because it classifies a large number of uneducated agricultural workers in early surveys as uneducated nonagricultural workers. Because we continue to use these workers' agricultural incomes while classifying them as nonagricultural workers, the income gain from moving from agriculture to non-agriculture will be underestimated. Related, nonagricultural returns to education will be biased upwards. In fact, we find that nonagricultural returns to education (Table 5) are 33.6 percent, ${ }^{17}$ about double the baseline case, while the gain from labor reallocation is only 60 percent of the baseline case. Even though the contribution of education through labor reallocation is biased downwards, row (4) of Table 9 shows that the impact of the reallocation channel continues to be more important than within-sector human capital growth (0.386 vs 0.237$)$.

\footnotetext{
${ }^{16}$ Because these individuals are older than 16 , we suspect their increased educational attainment is due to participation in the non-regular education system. Young (2003) argues that the quality of such institutions is questionable and excludes this type of education when quantifying the growth of human capital.

${ }^{17}$ Because we only observe agricultural income at the household level, we calculate individual incomes for workers who ultimately move into non-agriculture by dividing the household income across workers in proportion to their hours worked. This will overstate the income of uneducated agricultural workers classified as uneducated nonagricultural because it implicitly assumes no returns to education. However, because returns to education in the agricultural sector are less that 10 percent while the nonagriculture/agriculture income ratio is a factor of two to five, the estimated returns to education for nonagricultural workers primarily depends on the income differential.
} 


\subsubsection{Definition of Education}

A final alternative specification defines educated individuals as those who have completed high school rather than middle school. The last row of Table 9 shows that economic growth resulting from labor reallocation due to education is 0.168 percentage points per year, significantly lower than the baseline "no heterogeneity" specification (0.650). This change is largely the result of much slower growth in the share of high-school educated workers (0.33 vs 1.11 percentage points per year for those completing middle-school). Our estimates of economic growth within sectors also show small changes in the direction one would expect. Although education's total contribution to growth is lower, the labor reallocation continues to be the primary channel through which education affects growth.

\subsection{Relation to Other Approaches in Literature}

\subsubsection{Household- vs Individual-Level Returns to Education}

As discussed in Section 3, studies in the literature often estimate returns to education in the agricultural sector at the household-head level. We find that our estimates of household-head returns to education (columns (2) and (4) of Table 2) are higher than our baseline estimates of individual-level returns to education (column (2) of Tables 4 and 5). The reason for this is that 61 percent of workers in multiple-worker households have the same education level as their household head. Returns to education measured at the household-head level can thus be interpreted as individual-level returns weighted by the number of educated workers in the household.

\subsubsection{Level of Schooling}

To this point in our analysis we have simply classified individuals as either educated or uneducated rather than considering a finer gradation of education levels. We do this primarily to keep our estimation of the Roy model tractable but are aware that it may dampen our within-sector measures of human capital growth. We therefore consider a back-of-theenvelope calculation to examine the extent of the bias.

Specifically, we follow Young (2003) in considering four levels of education: none, primary, secondary, and tertiary. We use Young's estimates of returns to education in the nonagricul- 
tural sector and the number of nonagricultural workers of each education type (taken from the census) to construct the growth rate of human capital as described by Equations (2) and (3) but for four labor types. The resulting growth rate of human capital due to education is 0.258 percentage points. We then combine the two lowest and the two highest education groups and redo the calculation. The growth rate of human capital becomes 0.187 percentage points. ${ }^{18}$ Although within-sector human capital growth is smaller when we consider only two education levels, the increase in growth from allowing more education levels (0.07 percentage points) would not change our conclusion about the relative importance of the reallocation and human capital channels.

\subsubsection{Comparison with One-Sector Growth Accounting}

In the absence of evidence on sectoral levels of education in China, previous studies often employed a single education index and aggregate production function to assess education's contribution to growth (e.g., Bosworth and Collins 2008). Our finding that labor reallocation is an important channel through which education impacts growth raises the question of whether not explicitly taking multiple sectors into account will significantly alter the estimate of education's contribution. Although it is not possible to derive an analytical relationship showing how the results of the two-sector and one-sector approaches differ, we can use our data and estimates to make a rough calculation 19

Using our measures of sectoral returns to education and the distribution of workers across sector-education groups, we first construct an average (across sectors) return to education. ${ }^{20}$ This is simply the unconditional (on sector) expected income differential between an educated and uneducated worker. We then compute aggregate human capital growth by applying Equations (2) and (3) to a one-sector model. Our resulting estimate of human capital growth due to education, which equals the total contribution of education to growth in a one-sector setup, is 0.47 percent, whereas education's contribution in our two-sector model

\footnotetext{
${ }^{18}$ Our baseline measure of human capital growth due to education was 0.141 . We suspect our returns to education are lower than those estimated by Young (2003) because we add more control variables such as province-level characteristics.

${ }^{19}$ The analytical relationship cannot be derived because it is not possible to combine two sectoral production functions into one aggregate Cobb-Douglas production function if the labor share differs across sectors. We also can not directly compare our results to those of Bosworth and Collins (2008) because they assume a returns to education rather than estimating it.

${ }^{20}$ It can be shown that our approach of re-weighting sector-specific returns to education to get a measure of aggregate returns is equivalent to estimating aggregate returns by running one OLS regression on observations pooled together from both sectors.
} 
was 0.76 . This may indicate that a one-sector framework does not fully capture education's impact on growth through moving workers into the higher-productivity sector.

\section{Conclusion}

This paper examines education's role in accounting for recent Chinese economic growth through two channels: facilitating labor reallocation from the agricultural sector to the nonagricultural sector and increasing human capital within sectors. We find that increased education accounts for more than one-third of the growth attributable to labor reallocation. Overall, it accounts for about 11 percent of aggregate growth, and the labor reallocation channel (9 percent) was more important than the direct human capital channel (2 percent). We thus conclude that enabling labor reallocation is an important channel through which education can affect economic growth.

Our findings raise some interesting questions for future research. The first is assessing how important education's impact on labor reallocation has been for the growth experience of countries other than China. In order for education to affect growth through the labor reallocation channel, all that is needed is some labor market frictions which are less restrictive for educated workers. In particular, explicit regulations on labor mobility (as found in China) are not necessary for this channel to be operative. Although education's impact on labor reallocation may be exceptionally large in China because of the migration regulations, there is suggestive evidence that this channel could be quantitatively important in other developing countries. Many empirical papers, following Schultz (1971) and Todaro (1976), have documented substantial income differences between urban and rural areas in developing countries and have shown that educated workers are more likely to migrate into urban areas.

A second question considers the question of optimal government education and migration policy. Although allowing increased rural-to-urban migration may yield substantial income gains (and a more efficient allocation of labor inputs), large-scale migration could also impose substantial negative externalities on city dwellers, such as overcrowding and congestion effects. For a policymaker weighing the trade-off between increased economic growth and the negative externalities associated with migration, an optimal migration policy may condition

on education as a way of gradually allowing unrestricted labor movement. Although we make no claim on its optimality, especially in terms of how restrictive the migration policy should be, this is exactly the type of policy employed in China. 


\section{References}

Alfaro, L., A. Charlton, and F. Kanczuk (2008): "Plant-Size Distribution and CrossCountry Income Differences," NBER WP 14060.

Angrist, J. D., and A. B. Krueger (1991): "Does Compulsory School Attendance Affect Schooling and Earnings," Quarterly Journal of Economics, 106(1), 976-1014.

Ashenfelter, O., And C. Rouse (1999): "The Payoff to Education," Working paper, Princeton University.

Bartelsman, E., J. Haltiwanger, and S. Scarpetta (2008): "Cross Country Differences in Productivity: The Role of Allocative Efficiency," Working Paper, University of Maryland.

Benjamin, D., L. Brandt, P. Glewwe, and G. Li (2000): "Markets, Human Capital, and Inequality: Evidence from Rural China," Davidson Institute Working Paper 298.

Bergoeing, R., P. J. Kehoe, T. J. Kehoe, and R. Soto (2002): "A Decade Lost and Found: Mexico and Chile in the 1980s," Revies of Economic Dynamics, 5(1), 166-205.

Bils, M., and P. J. Klenow (2000): "Does Schooling Cause Growth," American Economic Review, 90(5), 1160-1183.

Bosworth, B., And S. M. Collins (2008): "Accounting for Growth: Comparing China and India," Journal of Economic Perspectives, 22(1), 45-66.

Brandt, L., C. Hsieh, and X. Zhu (2008): "Growth and Structural Transformation in China," in China's Great Economic Transformation, ed. by L. Brandt, and T. Rawski, pp. 683-728. Cambridge University Press, New York.

Caselli, F., and W. J. Coleman II (2001): "The U.S. Structural Transformation and Regional Convergence: A Reinterpretation," Journal of Political Economy, 109(3), 584616.

Chan, K. W., and W. Buckingham (2008): "Is China Abolishing the Hukou system?," The China Quarterly, 195.

Chan, K. W., And L. Zhang (1999): "The Hukou System and Rural-Urban Migration in China: Processes and Changes," The China Quarterly, 160, 818-855. 
De Brauw, A., And J. Giles (2008): "Migrant Opportunity and the Educational Attainment of Youth in Rural China," Working paper, Michigan State University.

De Mel, S., D. McKenzie, and C. M. Woodruff (2007): "Measuring Microenterprise Profits: Don't Ask How the Sausage is Made," World Bank Policy Research WP 4229.

Dekle, R., And G. VAndenbroucke (2006): “A Quantitative Analysis of China's Structural Transformation," Working paper, University of Iowa.

Hannum, E. (1999): "Political Change and the Urban-Rural Gap in Basic Education in China, 1949-1990," Comparative Education Review, 43(2), 193-211.

Hayashi, F., And E. C. Prescott (2008): "The Depressing Effect of Agricultural Institutions on the Prewar Japanese Economy," Journal of Political Economy, 116(4), 573-632.

Heckman, J. J., And B. E. Honore (1990): "The Empirical Content of the Roy Model," Econometrica, 58(5), 1121-1149.

Hsein, C.-T., And P. J. Klenow (forthcoming): "Misallocation and Manufacturing TFP in China and India," Quarterly Journal of Economics.

Klenow, P. J., and A. Rodriguez-Clare (1997): "The Neoclassical Revival in Growth Economics: Has It Gone Too Far?," in NBER Macroeconomics Annual 1997, ed. by B. S. Bernanke, and J. J. Rotemburg. MIT Press, Cambridge, MA.

Li, T., And J. Zhang (1998): "Returns to education under collective and household farming in China," Journal of Development Economics, 56(2), 307-335.

MaCurdy, T. (2007): "A Practitioner's Approach to Estimating Intertemporal Relationships Using Longitudinal Data: Lessons from Applications in Wage Dynamics," in Handbook of Econometrics, ed. by Z. Griliches, and M. Intriligator, vol. 6, pp. 4057-4167. Elsevier Science/North-Holland, Amsterdam.

Meng, X., And H. Wu (1994): "Household Income Determination and Regional Income Differentiation in Rural China," Working paper, Munich Personal RePEc Archive.

Mincer, J. (1974): Schooling, Experience, and Earnings. Columbia University Press, New York.

Parente, S. L., And E. C. Prescott (1994): "Barriers to Technology Adoption and Development," Journal of Political Economy, 102(2), 298-321. 
People's Republic of China. State Statistical Bureau. (1982, 1990, 1995, 2000, 2005): Population Census of China.China Statis. Pub. House, Beijing.

People's Republic of China. State Statistical Bureau. (annual issues): Chinese Statistical Yearbook.China Statis. Pub. House, Beijing.

Pepper, S. (1996): Radicalism and Education Reform in 20th-century China. Cambridge University Press, New York.

Restuccia, D., D. T. Yang, and X. Zhu (2008): "Agriculture and Aggregate Productivity: A Quantitative Cross-Country Analysis," Journal of Monetary Economics, 55(2), $234-250$.

Roy, A. D. (1951): "Some Thoughts on the Distribution of Earnings," Oxford Economic Papers, 3(2), 135-146.

Schultz, T. P. (1971): "Rural-Urban Migration in Colombia," The Review of Economics and Statistics, 53(2), 157-163.

Todaro, M. P. (1976): Internal Migration in Developing Countries. International Labour Office, Geneva.

Vollrath, D. (2009): "How Important are Dual Economy Effects for Aggregate Productivity," Journal of Development Economics, 88, 325-334.

Wang, F.-L. (2004): "Reformed Migration Control and New Targeted People: China's Hukou System in the 2000s," The China Quarterly, 177, 115-132.

- (2005): Organizing Through Division and Exclusion. Stanford University Press.

Willis, R. T., And S. Rosen (1979): "Education and Self-Selection," Journal of Political Economy, 87(5), S7-S36.

Wooldridge, J. M. (2001): Econometric Analysis of Cross Section and Panel Data. The MIT Press, Cambridge, MA.

YAnG, D. T., And M. Y. An (2002): "Human capital, entrepreneurship, and farm household earnings," Journal of Development Economics, 68(1), 65-88.

Young, A. (2003): "Gold into Base Metals: Productivity Growth in the People's Republic of China during the Reform Period," Journal of Political Economy, 111(6), 1220-1261. 
Zhaо, Y. (1997): "Labor Migration and Returns to Rural Education in China," American Journal of Agricultural Economics, 79(4), 1278-1283. 


\section{Appendix}

\section{A Definition of Variables}

- Sector: An individual is classified as an agricultural worker if her primary occupation is farming, fishing, or hunting.

- Annual Income: We construct income measures at the household level in the agricultural sector and at the individual level in the nonagricultural sector. In the agricultural sector, gross annual income includes both income earned from selling products and the market value of farm products consumed by the household. In the nonagricultural sector, income includes wages, bonuses, and subsidies for each individual. Individual subsidy income is constructed by dividing the household-level subsidy income, which aggregates subsidies for food, housing and other items, by the total number of workers in the household.

The reason we construct household rather than individual income in the agricultural sector is that, given our data, there is no satisfactory method for splitting household income between working members. For example, although we have a measure of the number of hours spent in agricultural production by each household member, we cannot construct individual-specific incomes by allocating household income proportionally to the number of hours worked by each member because this would imply no returns to education within a household.

\section{B Estimation Method}

\section{B.1 Unobserved Heterogeneity}

We use simulated method of moments to estimate the baseline model. We group the moments into five categories corresponding to agricultural- and nonagricultural-sector income, sector choice, education choice and the distribution of unobservable heterogeneity. Let $M$ denote a vector of moments partitioned into five groups: $M=\left[M^{1}, M^{2}, M^{3}, M^{4}, M^{5}\right]^{\prime}$. For the first four groups of moments, we use the difference between actual and predicted outcomes, 
multiplied by instruments that are observable variables in the corresponding equations. Assuming unobservable productivity $\mu \equiv\left\{\left[\mu_{a}(i), \mu_{n}(i)\right]^{\prime}\right\}_{i=1}^{I}$ is known, we can compute the first four groups of moments as follows:

$$
M^{j}(\mu)=\frac{1}{I_{j}} \sum_{i} w_{i} X_{i}^{j} 1_{i}^{j}\left(Y_{i}^{j}-\widehat{Y}_{i}^{j}(\mu)\right) \text { for } j=1,2,3,4
$$

where for $j=1,2, Y_{i}^{j}$ and $\widehat{Y}_{i}^{j}$ are actual and predicted income of agricultural $(j=1)$ and nonagricultural $(j=2)$ workers, for $j=3$, they are indicator functions that take a value of one if person $i$ works (or is predicted to work) in the nonagricultural sector, and for $j=4$, they take a value of one if person $i$ received (or was predicted to receive) education. $1_{i}^{j}$ is an indicator variable for whether person $i$ contributes to moment $j$ (i.e., for $j=1,1_{i}^{j}=1$ if $i$ is an agricultural worker), and $I_{j}$ is the total number of individuals who contribute to moment $j$. As discussed in Section 3 , the observations weights $w_{i}$ are set so that the sectoral composition of our sample matches that from national surveys.

For the last group of moments $M^{5}$, we use five moments related to the model's random variables (i.e., random shocks to income and unobservable heterogeneity). The first two moments are the variance (over time) of individual income in each of the two sectors, where income is demeaned by an individual's average income across years. The other three moments include the variance of mean income across workers in each sector (2 moments) and the mean income difference between the two sectors (1 moment).

Our computational algorithm works as follows. We first make an initial guess for the parameters, including the variances of $\mu_{a}$ and $\mu_{n}$. Given these variances, we draw 20 sets of $\left\{\left[\mu_{a}(i), \mu_{n}(i)\right]^{\prime}\right\}_{i=1}^{I}$ (i.e., unobservable productivities for all individuals). Given the productivity draws and parameters, we then compute the objective function, that is the sum of the squared residuals of the moments (i.e., $M^{\prime} M$ ). We use optimization algorithms to search for the parameter values which minimize the objective function, using 87 moments to pin down 87 parameter values of which 82 are coefficients of observable variables and 5 govern the distribution of random variables in the model. Note that because the model is exactly identified, the choice of weighting matrix does not affect the asymptotic efficiency of the estimates. The inference of the estimation follows Wooldridge (2001) and MaCurdy (2007). 


\section{B.2 No Unobserved Heterogeneity}

Our alternative specifications assume the error terms in Equations (6), (7) and (8) are uncorrelated. Specifically, the errors in the income processes are mean independent of an individual's education and sector. For the nonagricultural sector, we observe individual incomes and can estimate Equation (6) by taking the log of both sides of the equation and using weighted ordinary least squares. For the agricultural sector, we observe household-level income and therefore estimate Equation (9) using weighted nonlinear least squares.

After estimating the income process in both sectors, we construct fitted values of the present discounted value of income given the education and sector of each individual. We let $\widehat{V}_{s}^{E}(i)$ denote the fitted value. Then, given education and these fitted values, we can estimate the sector choice equation (Equation 7) as follows:

$$
\begin{aligned}
I(s=n \mid E) & \Longleftrightarrow \widehat{V}_{n}^{E}(i)-\widehat{V}_{a}^{E}(i)-C_{n}^{E}(i)>0 \\
& \Longleftrightarrow \frac{1}{\sigma_{\eta}}\left(\widehat{V}_{n}^{E}(i)-\widehat{V}_{a}^{E}(i)\right)-\theta Z(i)-\delta E(i)>\eta(i),
\end{aligned}
$$

where $I(s=n \mid E)$ is an indicator of sector choice. The estimated coefficient on $\widehat{V}_{n}^{E}(i)-\widehat{V}_{a}^{E}(i)$ is thus the inverse of the square root of the variance of $\eta$.

We can then estimate a worker's choice of education as follows:

$$
\begin{aligned}
I(E=1) & \Longleftrightarrow\left\{\widehat{V}^{1}(i)-\widehat{V}^{0}(i)\right\}-C_{e d u}(i)>0 \\
& \Longleftrightarrow \frac{1}{\sigma_{\nu}}\left\{\begin{array}{l}
\left(\widehat{V}_{n}^{1}(i) \times \widehat{\operatorname{Pr}}(n \mid 1)(i)+\widehat{V}_{a}^{1}(i) \times \widehat{\operatorname{Pr}}(a \mid 1)(i)\right)- \\
\left.\widehat{V}_{n}^{0}(i) \times \widehat{\operatorname{Pr}}(n \mid 0)(i)+\widehat{V}_{a}^{0}(i) \times \widehat{\operatorname{Pr}}(a \mid 0)(i)\right)
\end{array}\right\}-\kappa W(i)>\nu(i) .
\end{aligned}
$$

Finally, because regressors in the sector and educational choice equations are constructed from fitted values of the earnings equations, we compute bootstrapped standard errors.

\section{Growth Accounting Calculations}

\section{C.1 Within-sector growth from increased human capital}

We construct annual growth in human capital per worker due to increased educational attainment $\left(d \ln h_{s t}\right)$ as follows. As explained in Sections 3 and 4 , we use CHNS data to 
estimate time-invariant sectoral returns to middle-school education $\left(\gamma_{s}\right)$. Using census data, we construct the share of sector employees in each census year that were middle-school educated, and we interpolate to get annual shares $\left(l_{s t}^{e d u}, l_{s t}^{u n e d}\right)$. We use these inputs in Equations (2) and (3) - approximating $\gamma_{s t}$ with $\gamma_{s}$ - to compute the annual human capital per worker growth resulting from increased attainment of middle-school education.

As described in Section 2, the growth rate of human capital per worker translates onefor-one into the growth rate of output per worker $\left(d \ln y_{s t}\right)$. To construct the contribution to aggregate growth, we weight these growth rates by the respective sector's share of the

economy $\frac{y_{s t} l_{s t}}{y_{t}} \equiv \frac{Y_{s t}}{Y_{t}}$, which is constructed from annual data from the China Statistical Yearbooks (CSY). The resulting within-sector growth rates reported in the third panel of Table 9 are averages (across time) of these weighted growth rates.

\section{C.2 Labor Reallocation}

Recall that growth from labor reallocation is equal to the growth in the employment share of the nonagricultural sector weighted by the productivity differential across the sectors: $\frac{\left(y_{n t}-y_{a t}\right)}{y_{t}} d l_{n t}$ in Equation $\sqrt{1}$. For our purposes, we need to isolate the portion of the increased number of jobs and associated productivity gain that is attributable to increased educational attainment. We do this by multiplying the average growth in the share of educated workers by our estimates of education's impact on the probability of obtaining a nonagricultural sector job and the productivity gain that accompanies the job.

We construct the share of workers with a middle-school (or above) education from 1982 and 2005 Census data and then assume a constant growth rate of the educated share over that time period. We use CHNS data to estimate sector-specific income processes and a sector-choice equation and then use these estimates and our cross-sectional data to construct individual-specific counterfactual incomes and the increased probability of working in the nonagricultural sector associated with increased educational attainment. The income measures are then converted to productivity measures using average sectoral labor shares and individual-specific productivity gains from switching sectors are constructed. We take the product of the increased probability and the productivity gain, take the mean of this product across individuals, and take the average of this mean over time (six CHNS waves). Finally, we multiply this average by the average growth rate of the share of educated workers to arrive at our estimate of education's contribution to growth through labor reallocation. 
Table 1: CHNS Descriptive Statistics I

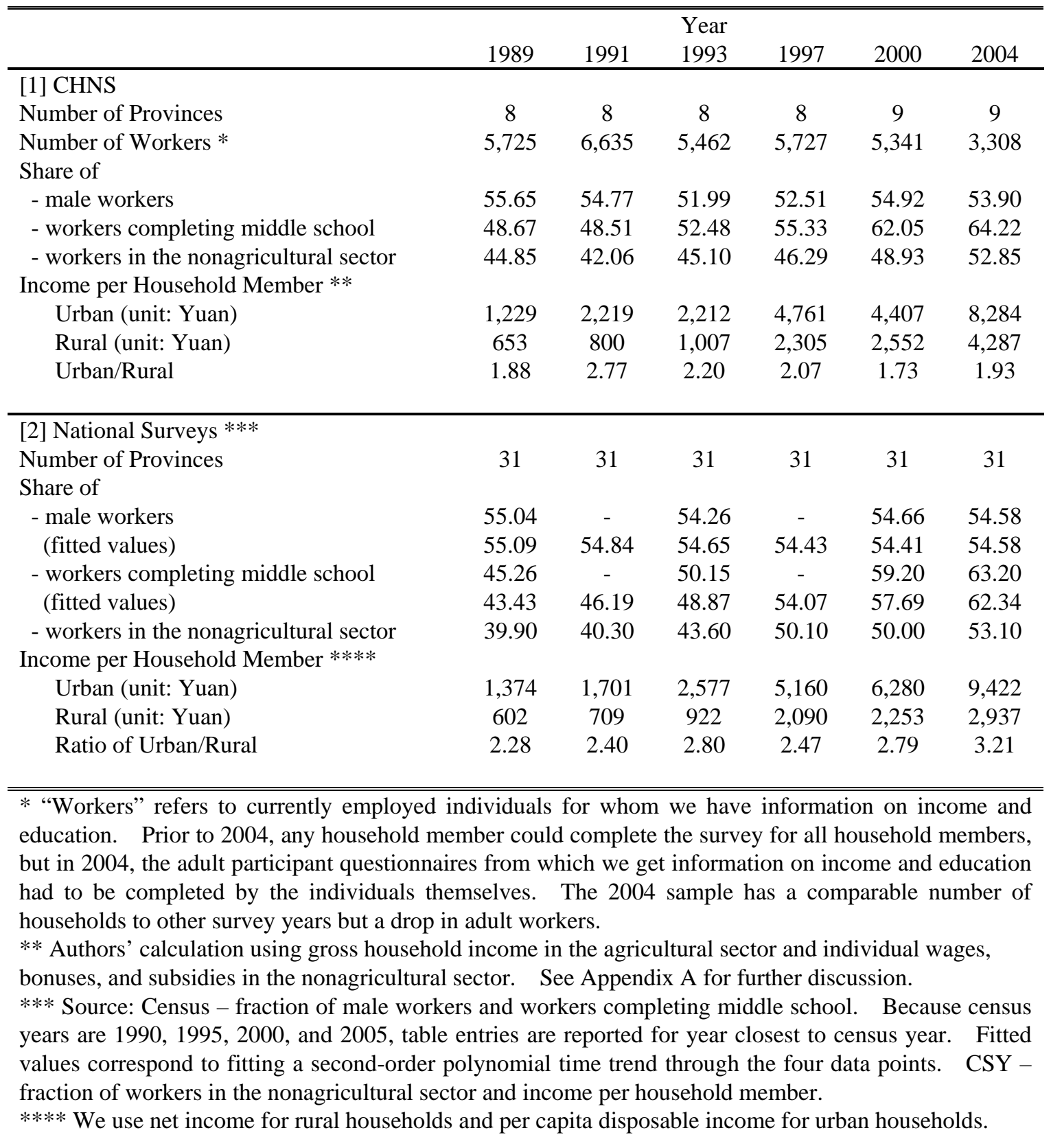


Table 2: CHNS Descriptive Statistics II

\begin{tabular}{|c|c|c|c|c|c|}
\hline & $\begin{array}{c}\text { (1) } \\
\text { Agriculture }\end{array}$ & $\begin{array}{c}\text { (2) } \\
\text { Agriculture }\end{array}$ & $\begin{array}{c}(3) \\
\text { Nonagriculture }\end{array}$ & $\begin{array}{c}\text { (4) } \\
\text { Nonagriculture }\end{array}$ & $\begin{array}{c}\text { (5) } \\
\text { Nonagriculture }\end{array}$ \\
\hline Years of Schooling & $\begin{array}{c}0.019 \\
{[0.005]^{* * *}}\end{array}$ & & $\begin{array}{c}0.051 \\
{[0.003]^{* * *}}\end{array}$ & & \\
\hline Primary School or Lower & & Base & & Base & \\
\hline Middle School or Higher & & $\begin{array}{c}0.082 \\
{[0.034]^{* *}}\end{array}$ & & $\begin{array}{c}0.245 \\
{[0.022]^{* * *}}\end{array}$ & \\
\hline None & & & & & $\begin{array}{c}-0.247 \\
{[0.031]^{* * *}}\end{array}$ \\
\hline Primary & & & & & Base \\
\hline Secondary & & & & & $\begin{array}{c}0.258 \\
{[0.020]^{* * *}}\end{array}$ \\
\hline Tertiatry & & & & & $\begin{array}{c}0.659 \\
{[0.028]^{* * *}}\end{array}$ \\
\hline Observations & 6,006 & 6,006 & 5,428 & 5,428 & 15,258 \\
\hline R-squared & 0.21 & 0.21 & 0.47 & 0.48 & 0.11 \\
\hline
\end{tabular}

Notes: Specifications (1) - (4) regress the log of income per household member on household head characteristics. Specifications (1) and (3) include years of schooling as a control variable, while specifications (2) and (4) have a dummy variable for whether the household head completed middle school. For specifications (1) - (4), covariates not listed in the table include age, age-squared, dummies for gender, race, marital status, and provincial fixed effects and provincial time trends. Specification (5) regresses individual incomes on dummy variables associated with educational degree, sex, and birth cohort, and coefficients are relative to the base group. Standard errors are in brackets (*significant at $10 \%$; ${ }^{* *}$ significant at $5 \%$; *** significant at $1 \%)$. 
Table 3: Migration and Education

\begin{tabular}{|c|c|c|c|c|}
\hline \multirow[t]{2}{*}{ Dependent Variable: } & $\begin{array}{c}(1) \\
\text { Migrant } \\
\text { (Inter or Intra } \\
\text { Province) }\end{array}$ & $\begin{array}{c}(2) \\
\text { Migrant } \\
\text { (Inter Province) }\end{array}$ & $\begin{array}{c}(3) \\
\text { Migrant } \\
\text { (Inter or Intra } \\
\text { Province) }\end{array}$ & $\begin{array}{c}(4) \\
\text { Migrant } \\
\text { (Inter Province) }\end{array}$ \\
\hline & OLS & OLS & OLS & OLS \\
\hline \multicolumn{5}{|l|}{ Educated } \\
\hline \multirow[t]{2}{*}{ - Middle School } & 0.120 & 0.043 & & \\
\hline & {$[0.014]^{* * *}$} & {$[0.008]^{* * *}$} & & \\
\hline \multirow[t]{2}{*}{ - High School } & & & 0.147 & 0.049 \\
\hline & & & {$[0.012]^{* * *}$} & {$[0.006]^{* * *}$} \\
\hline \multirow[t]{2}{*}{ Female } & 0.068 & -0.018 & 0.062 & -0.021 \\
\hline & {$[0.020]^{* * *}$} & {$[0.010]^{*}$} & {$[0.020]^{* * *}$} & {$[0.010]^{* *}$} \\
\hline \multirow[t]{2}{*}{ Minority } & 0.075 & -0.021 & 0.079 & -0.020 \\
\hline & {$[0.020]^{* * *}$} & {$[0.010]^{* *}$} & {$[0.019]^{* * *}$} & {$[0.010]^{*}$} \\
\hline \multirow[t]{2}{*}{ Fraction of urban hukou holders } & -0.529 & -0.483 & -0.540 & -0.487 \\
\hline & {$[0.182]^{* * *}$} & {$[0.095]^{* * *}$} & {$[0.181]^{* * *}$} & {$[0.095]^{* * *}$} \\
\hline \multirow[t]{2}{*}{ Fraction of nonagr workers } & 1.068 & 1.927 & 1.038 & 1.918 \\
\hline & {$[0.225]^{* * *}$} & {$[0.118]^{* * *}$} & {$[0.224]^{* * *}$} & {$[0.118]^{* * *}$} \\
\hline \multirow[t]{2}{*}{ Fraction of state firms } & 0.083 & -1.273 & 0.135 & -1.257 \\
\hline & [0.188] & {$[0.099]^{* * *}$} & [0.187] & {$[0.098]^{* * *}$} \\
\hline Observations & 5,350 & 5,350 & 5,350 & 5,350 \\
\hline R-squared & 0.09 & 0.16 & 0.10 & 0.16 \\
\hline
\end{tabular}

Notes: Other control variables include provincial and cohort fixed effects. The unit of observation is (household head $\mathrm{x}$ year). Standard errors are in brackets (*significant at 10\%; ** significant at 5\%; *** significant at $1 \%$ ). 
Table 4: Returns to Education in the Agricultural Sector

\begin{tabular}{lccccc}
\hline \hline & $(1)$ & $(2)$ & $(3)$ & $(4)$ & $(5)$ \\
& Heterogeneity & No Heterogeneity & Time Varying & Incl. Changers & High school \\
& SMM & NLS & NLS & NLS & NLS \\
\hline Education & 0.101 & 0.068 & -0.089 & 0.089 & 0.066 \\
& {$[0.099]$} & {$[0.027]^{* *}$} & {$[0.044]^{* *}$} & {$[0.028]^{* * *}$} & {$[0.053]$} \\
Education*year & & 0.019 & & \\
& & & & \\
Age/100 & 9.508 & 9.230 & {$[0.005]^{* * *}$} & & \\
& {$[1.184]^{* * *}$} & {$[0.045]^{* * *}$} & {$[0.683]^{* * *}$} & {$[0.157]^{* * *}$} & {$[0.053]^{* * *}$} \\
Age ${ }^{2} / 10000$ & -10.447 & -10.567 & -10.123 & -10.558 & -10.567 \\
& {$[0.536]^{* * *}$} & {$[0.048]^{* * *}$} & {$[0.806]^{* * *}$} & {$[0.168]^{* * *}$} & {$[0.053]^{* * *}$} \\
Female & 0.245 & 0.234 & 0.238 & 0.114 & 0.236 \\
& {$[0.022]^{* * *}$} & {$[0.035]^{* * *}$} & {$[0.032]^{* * *}$} & {$[0.034]^{* * *}$} & {$[0.035]^{* * *}$} \\
Minority & 0.013 & 0.157 & 0.157 & 0.131 & 0.158 \\
& {$[0.026]$} & {$[0.034]^{* *}$} & {$[0.030]^{* * *}$} & {$[0.032]^{* * *}$} & {$[0.035]^{* * *}$} \\
Married & 0.093 & 0.216 & 0.224 & 0.198 & 0.221 \\
& {$[0.064]^{* *}$} & {$[0.034]^{* * *}$} & {$[0.035]^{* * *}$} & {$[0.033]^{* * *}$} & {$[0.036]^{* * *}$} \\
Year & 0.069 & 0.113 & 0.108 & 0.109 & 0.114 \\
& {$[0.075]$} & {$[0.006]^{* * *}$} & {$[0.006]^{* * *}$} & {$[0.005]^{* * *}$} & {$[0.006]^{* * *}$} \\
\hline Observations & 7,715 & 7,715 & 7,715 & 8,286 & 7,715 \\
R-squared & -- & 0.23 & 0.23 & 0.22 & 0.23 \\
\hline \hline
\end{tabular}

Notes: The dependent variable is the log of household agricultural income, and the unit of observation is (household $x$ year). Covariates not listed in the table include provincial fixed effects and provincial time trends. Standard errors are in brackets (*significant at $10 \%$; ** significant at 5\%; $* * *$ significant at $1 \%$ ). Standard errors and significance level for models (2) - (5) are based on a bootstrap with 100 replications. 
Table 5: Returns to Education in the Nonagricultural Sector

\begin{tabular}{|c|c|c|c|c|c|}
\hline & $\begin{array}{c}\text { (1) } \\
\text { Heterogeneity } \\
\text { SMM }\end{array}$ & $\begin{array}{c}\text { (2) } \\
\text { No Heterogeneity } \\
\text { OLS }\end{array}$ & $\begin{array}{c}\text { (3) } \\
\text { Time Varying } \\
\text { OLS }\end{array}$ & $\begin{array}{c}\text { (4) } \\
\text { Incl. Changers } \\
\text { OLS }\end{array}$ & $\begin{array}{c}\text { (5) } \\
\text { High school } \\
\text { OLS }\end{array}$ \\
\hline Education & $\begin{array}{c}0.142 \\
{[0.066]^{* * *}}\end{array}$ & $\begin{array}{c}0.171 \\
{[0.022]^{* * *}}\end{array}$ & $\begin{array}{c}0.091 \\
{[0.024]^{* * *}}\end{array}$ & $\begin{array}{c}0.336 \\
{[0.025]^{* * *}}\end{array}$ & $\begin{array}{c}0.163 \\
{[0.012]^{* * *}}\end{array}$ \\
\hline Education*Year & & & $\begin{array}{c}0.014 \\
{[0.004]^{* * *}}\end{array}$ & & \\
\hline Age/100 & $\begin{array}{c}4.973 \\
{[0.086]^{* * *}}\end{array}$ & $\begin{array}{c}4.964 \\
{[0.431]^{* * *}}\end{array}$ & $\begin{array}{c}4.923 \\
{[0.401]^{* * *}}\end{array}$ & $\begin{array}{c}6.776 \\
{[0.582]^{* * *}}\end{array}$ & $\begin{array}{c}3.972 \\
{[0.411]^{* * *}}\end{array}$ \\
\hline $\mathrm{Age}^{2} / 10000$ & $\begin{array}{c}-5.276 \\
{[0.131]^{* * *}}\end{array}$ & $\begin{array}{c}-5.276 \\
{[0.547]^{* * *}}\end{array}$ & $\begin{array}{c}-5.246 \\
{[0.492]^{* * *}}\end{array}$ & $\begin{array}{c}-6.911 \\
{[0.700]^{* * *}}\end{array}$ & $\begin{array}{c}-4.175 \\
{[0.505]^{* * *}}\end{array}$ \\
\hline Female & $\begin{array}{c}-0.139 \\
{[0.009]^{* * *}}\end{array}$ & $\begin{array}{c}-0.139 \\
{[0.010]^{* * *}}\end{array}$ & $\begin{array}{c}-0.140 \\
{[0.010]^{* * *}}\end{array}$ & $\begin{array}{c}-0.034 \\
{[0.012]^{* * *}}\end{array}$ & $\begin{array}{c}-0.148 \\
{[0.010]^{* * *}}\end{array}$ \\
\hline Minority & $\begin{array}{c}-0.066 \\
{[0.012]^{* * *}}\end{array}$ & $\begin{array}{c}-0.034 \\
{[0.023]^{*}}\end{array}$ & $\begin{array}{c}-0.034 \\
{[0.020]^{* *}}\end{array}$ & $\begin{array}{c}-0.065 \\
{[0.025]^{* *}}\end{array}$ & $\begin{array}{c}-0.067 \\
{[0.020]^{* *}}\end{array}$ \\
\hline Married & $\begin{array}{l}-0.012 \\
{[0.022]}\end{array}$ & $\begin{array}{c}0.010 \\
{[0.019]}\end{array}$ & $\begin{array}{c}0.012 \\
{[0.020]}\end{array}$ & $\begin{array}{c}-0.053 \\
{[0.027]^{* * *}}\end{array}$ & $\begin{array}{c}0.030 \\
{[0.021]}\end{array}$ \\
\hline Year & $\begin{array}{c}0.103 \\
{[0.000]^{* * *}}\end{array}$ & $\begin{array}{c}0.102 \\
{[0.002]^{* * *}}\end{array}$ & $\begin{array}{c}0.090 \\
{[0.005]^{* * *}}\end{array}$ & $\begin{array}{c}0.106 \\
{[0.003]^{* * *}}\end{array}$ & $\begin{array}{c}0.104 \\
{[0.003]^{* * *}}\end{array}$ \\
\hline Observations & 13,091 & 13,091 & 13,091 & 15,855 & 13,091 \\
\hline R-squared & -- & 0.57 & 0.57 & 0.44 & 0.56 \\
\hline
\end{tabular}

Notes: The dependent variable is the log of individual income, and the unit of observation is (individual $\mathrm{x}$ year) Covariates not listed in the table include provincial fixed effects and provincial time trends. Standard errors are in brackets (*significant at $10 \%$; $* *$ significant at $5 \%$; *** significant at $1 \%$ ). Standard errors and significance level for models (2) - (5) are based on a bootstrap with 100 replications. 
Table 6: Choice of Sector

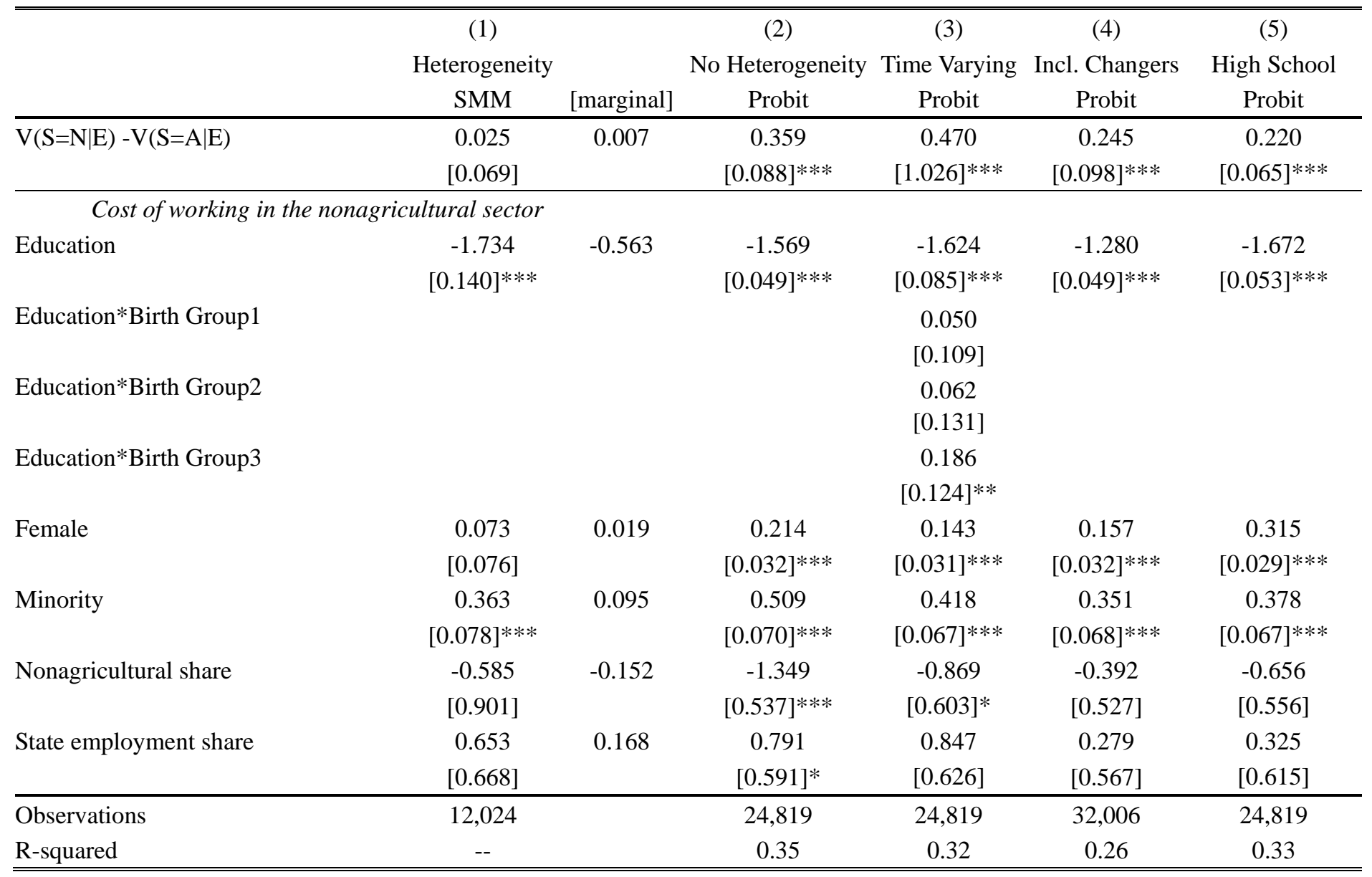

Notes: The dependent variable is an indicator of whether the worker has a nonagricultural job. The unit of observation is the individual for specification (1) and (individual x year) for the rest. All specifications include constants and dummy variables for birth-year group. Standard errors are in brackets (*significant at 10\%; ** significant at 5\%; *** significant at 1\%). Standard errors and significance level for models (2) - (5) are based on a bootstrap with 100 replications. For specification (3), the omitted birth group includes people born before 1948, and birth groups 1 - 3 include people born between 1948 and 1955, 1956 and 1965, and after 1965, respectively. 
Table 7: Choice of Education

\begin{tabular}{lcccccc}
\hline \hline & $(1)$ & & $(2)$ & $(3)$ & $(4)$ & $(5)$ \\
& Heterogeneity & & No Heterogeneity & Time varying & Incl. Changes & High School \\
& SMM & [Marginal] & Probit & Probit & Probit & Probit \\
\hline $\mathrm{V}^{1}-\mathrm{V}^{0}$ & 1.072 & 0.300 & 1.181 & 1.595 & 3.027 & 0.376 \\
& {$[20.932]$} & & {$[0.329]^{* * *}$} & {$[0.309]^{* * *}$} & {$[0.286]^{* * *}$} & {$[0.158]^{*}$} \\
\hline Cost of education & & & & & \\
Female & 0.480 & 0.147 & 0.467 & 0.389 & 0.487 & 0.162 \\
Minority & {$[1.251]$} & & {$[0.081]^{* * *}$} & {$[0.046]^{* * *}$} & {$[0.042]^{* * *}$} & {$[0.068]^{* * *}$} \\
& -0.214 & -0.067 & -0.239 & -0.294 & 0.040 & 0.093 \\
No. enrolled student & {$[6.974]$} & & {$[0.148]^{* * *}$} & {$[0.107]$} & {$[0.076]$} & {$[0.098]^{*}$} \\
& -0.196 & -0.061 & -0.002 & -0.002 & -0.146 & -0.000 \\
\hline Observations & {$[0.227]$} & & {$[0.031]^{* * *}$} & {$[0.035]^{* * *}$} & {$[0.025]^{* * *}$} & {$[0.028]$} \\
R-squared & 12,024 & & 24,819 & 24,819 & 32,006 & 24,819 \\
\hline \hline
\end{tabular}

Notes: The dependent variable is an indicator of whether the worker has obtained a certain level of education (high school for (5); middle school for the rest). The unit of observation is the individual for specification (1) and (individual $\mathrm{x}$ year) for the rest. All specifications include constants and dummy variables for birth-year groups. Standard errors are in brackets (*significant at 10\%; ** significant at 5\%; *** significant at 1\%). Standard errors and significance levels for models (2) - (5) are based on a bootstrap with 100 replications. 
Table 8: Additional Parameter Estimates for Model with Unobserved Heterogeneity

\begin{tabular}{lcl}
\hline \hline Variable & Estimates & \multicolumn{1}{c}{ se } \\
\hline$\sigma_{\mu, a}$ & 3.235 & {$[0.248]^{* * *}$} \\
$\sigma_{\mu, n}$ & 0.388 & {$[0.322]$} \\
$\rho\left(\mu_{a}, \mu_{n}\right)$ & 0.388 & {$[22.201]$} \\
$\sigma_{\varepsilon, a}$ & 3.640 & {$[0.033]^{* * *}$} \\
$\sigma_{\varepsilon, n}$ & 0.145 & {$[0.000]^{* * *}$} \\
\hline \hline
\end{tabular}

Sum of squared residuals: 0.00046 
Table 9: Education's Contribution to Growth

\begin{tabular}{|c|c|c|c|c|c|c|c|c|}
\hline & & & & \multicolumn{5}{|c|}{ Unit: percent } \\
\hline & (1) & $(2)$ & (3) & (4) & (5) & (6) & $(7)$ & $(8)$ \\
\hline & Aggregate & Agriculture & Nonagriculture & Reallocation & Reallocation & Reallocation & Reallocation & Reallocation \\
\hline Growth rate of output per worker & & & & Baseline & No Corr & $\mathrm{y}^{\mathrm{ed}}(\mathrm{i})-\mathrm{y}^{\mathrm{un}}(\mathrm{i})$ & $\begin{array}{l}\mathrm{y}_{\mathrm{n}}-\mathrm{y}_{\mathrm{a}} \\
\mathrm{CHNS} \\
\end{array}$ & $\begin{array}{c}\mathrm{y}_{\mathrm{n}}-\mathrm{y}_{\mathrm{a}} \\
\mathrm{CSY} \\
\end{array}$ \\
\hline Young (1978 1998) & 5.2 & & 3.6 & & & & & \\
\hline Brandt et al. (1978 2004) & 7.0 & 6.8 & 4.7 & & & & & \\
\hline Dekle \& Vandenbrouke (1978 2003) & 5.7 & 4.5 & 4.1 & & & & & \\
\hline \multicolumn{9}{|l|}{ Growth Decomposition } \\
\hline \multirow[t]{2}{*}{ Brandt et al. (1978 2004) } & 7.0 & 1.9 & 3.4 & 1.7 & & & & \\
\hline & $(100.0)$ & $(27.3)$ & $(48.1)$ & $(24.6)$ & & & & \\
\hline \multirow[t]{2}{*}{ Dekle \& Vandenbrouke (1978 2003) } & 5.7 & 0.8 & 3.0 & 1.9 & & & & \\
\hline & $(100.0)$ & $(14.1)$ & $(52.6)$ & $(33.3)$ & & & & \\
\hline \multicolumn{9}{|l|}{ Contribution of Education (1978 2004) } \\
\hline (1) Heterogeneity & 0.793 & 0.034 & 0.107 & 0.652 & 0.636 & 0.761 & 0.896 & 0.862 \\
\hline (\% of the avg. growth) & $(11.40)$ & $(0.49)$ & $(1.54)$ & $(9.37)$ & $(9.14)$ & $(10.94)$ & (12.87) & (12.39) \\
\hline (\% of each of the element in Brandt et al) & & {$[1.79]$} & {$[3.20]$} & {$[38.08]$} & {$[37.15]$} & {$[44.47]$} & {$[52.32]$} & {$[50.36]$} \\
\hline \multicolumn{9}{|l|}{ Alternative Models } \\
\hline (2) No Heterogeneity & 0.798 & 0.026 & 0.122 & 0.650 & 0.584 & 0.772 & 0.822 & 0.792 \\
\hline (3) Time varying & 0.740 & 0.005 & 0.114 & 0.621 & 0.506 & 0.671 & 0.712 & 0.686 \\
\hline (4) Incl. Changers & 0.623 & 0.031 & 0.206 & 0.386 & 0.498 & 0.566 & 0.702 & 0.677 \\
\hline (5) High school & 0.311 & 0.000 & 0.143 & 0.168 & 0.172 & 0.239 & 0.243 & 0.235 \\
\hline
\end{tabular}

Notes: The aggregate contribution of education (column (1) of the third panel) is simply the sum of columns (2) - (4). Columns (5) - (8) present alternative measures of growth due to reallocation as described in Section 4.3. 
Table 9: Education's Contribution to Growth

\begin{tabular}{|c|c|c|c|c|c|c|c|c|}
\hline & & & & \multicolumn{5}{|c|}{ Unit: percent } \\
\hline & (1) & $(2)$ & (3) & (4) & (5) & (6) & $(7)$ & $(8)$ \\
\hline & Aggregate & Agriculture & Nonagriculture & Reallocation & Reallocation & Reallocation & Reallocation & Reallocation \\
\hline Growth rate of output per worker & & & & Baseline & No Corr & $\mathrm{y}^{\mathrm{ed}}(\mathrm{i})-\mathrm{y}^{\mathrm{un}}(\mathrm{i})$ & $\begin{array}{l}\mathrm{y}_{\mathrm{n}}-\mathrm{y}_{\mathrm{a}} \\
\mathrm{CHNS} \\
\end{array}$ & $\begin{array}{c}\mathrm{y}_{\mathrm{n}}-\mathrm{y}_{\mathrm{a}} \\
\mathrm{CSY} \\
\end{array}$ \\
\hline Young (1978 1998) & 5.2 & & 3.6 & & & & & \\
\hline Brandt et al. (1978 2004) & 7.0 & 6.8 & 4.7 & & & & & \\
\hline Dekle \& Vandenbrouke (1978 2003) & 5.7 & 4.5 & 4.1 & & & & & \\
\hline \multicolumn{9}{|l|}{ Growth Decomposition } \\
\hline \multirow[t]{2}{*}{ Brandt et al. (1978 2004) } & 7.0 & 1.9 & 3.4 & 1.7 & & & & \\
\hline & $(100.0)$ & $(27.3)$ & $(48.1)$ & $(24.6)$ & & & & \\
\hline \multirow[t]{2}{*}{ Dekle \& Vandenbrouke (1978 2003) } & 5.7 & 0.8 & 3.0 & 1.9 & & & & \\
\hline & $(100.0)$ & $(14.1)$ & $(52.6)$ & $(33.3)$ & & & & \\
\hline \multicolumn{9}{|l|}{ Contribution of Education (1978 2004) } \\
\hline (1) Heterogeneity & 0.793 & 0.034 & 0.107 & 0.652 & 0.636 & 0.761 & 0.896 & 0.862 \\
\hline (\% of the avg. growth) & $(11.40)$ & $(0.49)$ & $(1.54)$ & $(9.37)$ & $(9.14)$ & $(10.94)$ & (12.87) & (12.39) \\
\hline (\% of each of the element in Brandt et al) & & {$[1.79]$} & {$[3.20]$} & {$[38.08]$} & {$[37.15]$} & {$[44.47]$} & {$[52.32]$} & {$[50.36]$} \\
\hline \multicolumn{9}{|l|}{ Alternative Models } \\
\hline (2) No Heterogeneity & 0.798 & 0.026 & 0.122 & 0.650 & 0.584 & 0.772 & 0.822 & 0.792 \\
\hline (3) Time varying & 0.740 & 0.005 & 0.114 & 0.621 & 0.506 & 0.671 & 0.712 & 0.686 \\
\hline (4) Incl. Changers & 0.623 & 0.031 & 0.206 & 0.386 & 0.498 & 0.566 & 0.702 & 0.677 \\
\hline (5) High school & 0.311 & 0.000 & 0.143 & 0.168 & 0.172 & 0.239 & 0.243 & 0.235 \\
\hline
\end{tabular}

Notes: The aggregate contribution of education (column (1) of the third panel) is simply the sum of columns (2) - (4). Columns (5) - (8) present alternative measures of growth due to reallocation as described in Section 4.3. 